\title{
IL-1 $\beta$ in eosinophil-mediated small intestinal homeostasis and IgA production
}

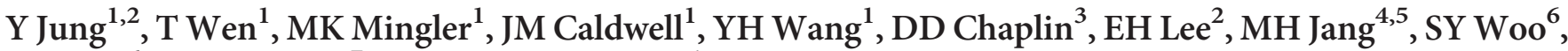 \\ JY Seoh ${ }^{6}, \mathrm{M} \mathrm{Miyasaka}^{7}$ and ME Rothenberg ${ }^{1}$
}

Eosinophils are multifunctional leukocytes that reside in the gastrointestinal (GI) lamina propria, where their basal function remains largely unexplored. In this study, by examining mice with a selective deficiency of systemic eosinophils (by lineage ablation) or GI eosinophils (eotaxin-1/2 double deficient or CC chemokine receptor 3 deficient), we show that eosinophils support immunoglobulin A ( $\lg A)$ class switching, maintain intestinal mucus secretions, affect intestinal microbial composition, and promote the development of Peyer's patches. Eosinophil-deficient mice showed reduced expression of mediators of secretory IgA production, including intestinal interleukin $1 \beta$ (IL-1ß), inducible nitric oxide synthase, lymphotoxin (LT) $\alpha$, and LT- $\beta$, and reduced levels of retinoic acid-related orphan receptor gamma t-positive $\left(\mathrm{ROR}-\gamma \mathrm{t}^{+}\right.$) innate lymphoid cells (ILCs), while maintaining normal levels of APRIL (a proliferation-inducing ligand), BAFF (B cell-activating factor of the tumor necrosis factor family), and TGF- $\beta$ (transforming growth factor $\beta$ ). Gl eosinophils expressed a relatively high level of IL-1 $\beta$, and IL-1 $\beta$-deficient mice manifested the altered gene expression profiles observed in eosinophil-deficient mice and decreased levels of IgA ${ }^{+}$cells and ROR- $\gamma^{+}{ }^{+}$ILCs. On the basis of these collective data, we propose that eosinophils are required for homeostatic intestinal immune responses including IgA production and that their affect is mediated via IL-1 $\beta$ in the small intestine.

\section{INTRODUCTION}

Eosinophils have been considered to be end-stage effector cells that have an important role in parasitic infections and allergic inflammations. ${ }^{1}$ However, numerous lines of evidence indicate that eosinophils are multifunctional leukocytes involved not only in modulation of innate and adaptive immunity, but also in various biological processes. ${ }^{2,3}$

Eosinophils develop in the bone marrow and migrate to the lamina propria (LP) of the gastrointestinal (GI) tract under homeostatic conditions. ${ }^{4}$ The intestinal immune system is a unique environment that invokes strong protective immunity against pathogens, while maintaining tolerance to dietary proteins or commensal bacteria. ${ }^{5}$ A prominent feature of the intestinal immune system is the neutralization of harmful pathogens by production of immunoglobulin (Ig) A, the most abundant human antibody isotype, ${ }^{6}$ which is normally deposited as secretory $\operatorname{IgA}(\mathrm{S} \operatorname{IgA})$ in the intestinal lumen. IgA can be induced by T cell-dependent or T cell-independent pathways, which mainly occur in the organized lymphoid tissue of Peyer's patches (PP) and in the LP of the small intestine, respectively. ${ }^{7} \mathrm{~T}$ cell-dependent IgA production depends on cluster of differentiation (CD) 40 signals of $\mathrm{CD}^{+} \mathrm{T}$ cells activated by dendritic cells (DCs) under the influence of cytokines, in particular transforming growth factor $\beta$ (TGF- $\beta$, $T g f b 1) .{ }^{7,8} \mathrm{~T}$ cell-independent IgA class switching of B cells is induced by various cytokines in the LP, mainly by APRIL (a proliferation-inducing ligand, Tnfsf13) and BAFF (B cellactivating factor of the tumor necrosis factor family, Tnfsf $13 b){ }^{7,9}$ Local production of nitric oxide via inducible nitric oxide synthase (iNOS, Nos2), which regulates the expression of activation-induced deaminase and IgA germinal transcript, also has a role in IgA class switching in the LP of the

\footnotetext{
${ }^{1}$ Division of Allergy and Immunology, Cincinnati Children's Hospital Medical Center, University of Cincinnati College of Medicine, Cincinnati, Ohio, USA. ${ }^{2}$ Department of Microbiology, Graduate School of Medicine, Gachon University, Incheon, Republic of Korea. ${ }^{3}$ Department of Microbiology, University of Alabama at Birmingham, Birmingham, Alabama, USA. ${ }^{4}$ Academy of Immunology and Microbiology, Institute for Basic Science, Pohang, Republic of Korea. ${ }^{5}$ Division of Integrative Biosciences and Biotechnology, Pohang University of Science and Technology, Pohang, Republic of Korea. ${ }^{6}$ Department of Microbiology, Graduate School of Medicine, Ewha Womans University, Seoul, Republic of Korea and ${ }^{7}$ WPI Immunology Frontier Research Center, Osaka University, Suita, Japan. Correspondence: ME Rothenberg (Rothenberg@cchmc.org)
} 
small intestine. ${ }^{10,11}$ Recently, lymphotoxin (LT) $\alpha$ (Lta) and LT- $\beta(L t b)$ produced by retinoic acid-related orphan receptor gamma t-positive (ROR- $\gamma \mathrm{t}^{+}$) innate lymphoid cells (ILCs) have been shown to regulate IgA production in the small intestine. $^{12}$

Murine eosinophils in the bone marrow support the survival of plasma cells by secreting APRIL and interleukin (IL) $6 .{ }^{13}$ Although the involvement of intestinal eosinophils in IgA class switching has not yet been directly examined, the impaired IgA production in CD47-deficient mice suggests a potential role of intestinal eosinophils in IgA synthesis, ${ }^{14}$ as small intestinal eosinophils highly express an inhibitory receptor signal regulatory protein- $\alpha$, a cognate receptor for CD47, and signal regulatory protein- $\alpha / \mathrm{CD} 47$ signaling contributes to the prolonged survival of murine intestinal eosinophils by inhibiting their degranulation. ${ }^{15}$ In the healthy state, eosinophils are barely present in the $\mathrm{PP},{ }^{16}$ where $\mathrm{T}$ cell-dependent IgA class switching takes place. Therefore, it seems plausible that eosinophils contribute to T cell-independent IgA class switching by modulating the immune environment of the small intestinal LP, where abundant numbers of eosinophils co-reside with plasma cells. ${ }^{4,9}$

In the present study, we investigated the role of eosinophils in the production of SIgA in the GI tract. Using four different strains of mice with absent or reduced GI eosinophils caused by independent gene deletions (i.e., two eosinophil lineageablated (PHIL (mice expressing cytocidal diphtheria toxin in a promoter of the Epx) and $\triangle$ dblGATA (mice carrying a targeted deletion of a double palindromic GATA-1 binding site in the Gata1 promoter)), eotaxin-1/eotaxin-2 double knockout (Ccl11/Ccl24 DKO), and CC chemokine receptor (CCR) 3 knockout $(\mathrm{Ccr} 3 \mathrm{KO})$ mice), we demonstrate that IgA ${ }^{+}$cells are significantly decreased in the absence of eosinophils. In addition, eosinophil-deficient mice have reduced mucus production and PP size, and alterations in commensal intestinal microbiota and oral tolerance induction. Although the expression of intestinal Tnfsf13, Tnfsf13b, and $T g f b 1$ were not affected by the deficiency of eosinophils, there was a decrease in intestinal Illb (gene for IL-1 $\beta$ ), Lta, Ltb, and Nos2 expression, as well as ROR- $\gamma \mathrm{t}^{+}$ILCs. In line with reduced $I l 1 b$ in eosinophil-deficient mice and with small intestinal eosinophils being a major source of $I l 1 b$, IL-1 $\beta$-deficient (Il1b KO) mice demonstrated decreased intestinal IgA. Collectively, our findings demonstrate that GI eosinophils regulate intestinal adaptive immune responses, mainly SIgA production, and we propose that this regulation involves an IL- $1 \beta$-dependent mechanism involving eosinophil-dependent changes in commensal microbiota.

\section{RESULTS}

$\lg \mathrm{A}^{+}$plasma cells are significantly decreased in the small intestine of eosinophil-deficient mice

We first demonstrated that eosinophil-deficient mice, as modeled by $\Delta$ dblGATA, Ccr3 KO, Ccl11/Ccl24 DKO, and PHIL, had a marked decrease in small intestinal eosinophils defined by $\mathrm{CD} 11 \mathrm{~b}^{\text {high }} \mathrm{CD} 11 \mathrm{c}^{\text {int }}$ markers (Figure 1a). ${ }^{17} \mathrm{~A}$ significant reduction of $\operatorname{IgA}$ in the serum and intestinal lavage was observed in $\triangle$ dblGATA, $C c r 3 \mathrm{KO}$, and $C c l 11 / C c l 24 \mathrm{DKO}$ mice (Figure 1b). To substantiate that the decrease of IgA is due to the absence of eosinophils, we examined IgA levels in PHIL mice, designed to deplete eosinophils by lineage-specific expression of the cytocidal diphtheria toxin A. ${ }^{18}$ Significantly, decreased serum and intestinal IgA levels were also observed in PHIL mice (Figure 1b). Reduced IgA in eosinophil-deficient mice was reflected by decreases in the frequency and number of $\mathrm{IgA}^{+} \mathrm{B} 220^{-}$cells in the LP of the small intestine and of $\mathrm{IgA}^{+} \mathrm{B}_{220^{+}}$cells (post-class switch recombination (postCSR) $\left.\operatorname{IgA}^{+} \mathrm{B}_{\text {cells }}\right)^{10}$ in the PP of these mice (Figure 1c). The increase of $\mathrm{IgM}^{+} \mathrm{B} 220^{+}$cells in the small intestine and the decreased germinal center $\mathrm{IgA}^{+}$cells expressing peanut agglutinin in the PP of $\triangle$ dblGATA mice also indicated impaired IgA class switching (Supplementary Figure S1A and $\mathbf{B}$ online). However, the presence of eosinophils in the culture of total LP cells had no supportive effect on the survival of $\mathrm{IgA}^{+}$cells (Supplementary Figure S1C). In addition, it is unlikely that the B cells of $\triangle$ dblGATA are defective in IgA class switching as the expression of activation-induced deaminase and IgA germinal transcript were not impaired in B cells of $\triangle$ dblGATA under IgA CSR-inducing conditions (Supplementary Figure S1D and E). In the mesenteric lymph nodes (MLN), no differences were observed in the frequency and number of post-CSR IgA ${ }^{+}$cells (Figure 1c; data not shown). In the PP, CD40-expressing B cells undergo IgA CSR in response to CD40 ligand (CD40L) signal from T cells. ${ }^{7}$ However, the frequencies of CD40-expressing B cells and CD40L-expressing $\mathrm{T}$ cells were not affected in the PP of $\triangle \mathrm{dblGATA}, C \mathrm{cr} 3 \mathrm{KO}$, and $C c l 11 /$ Ccl24 DKO mice (data not shown). In addition, integrin $\alpha 4 \beta 7$ and CCR9, molecules associated with homing of post-CSR $\mathrm{IgA}^{+}$cells to the small intestine, were comparably detected in IgA ${ }^{+}$plasma cells isolated from the small intestine of wild-type (WT) and eosinophil-deficient mice (data not shown).

\section{PP and small intestinal immune cell populations in eosinophil-deficient mice and impaired PP development}

Analysis of the small intestinal LP cells by flow cytometry demonstrated a significant decrease in the total cell number in $\Delta$ dblGATA, Ccr3 KO, Ccl11/Ccl24 DKO, and PHIL mice (Figure 2a); but no decrease in the frequency of $\mathrm{CD} 4^{+}, \mathrm{CD} 8^{+}$, or $\mathrm{CD} 19^{+}$cells or DCs or plasmacytoid DCs (pDCs) in any of the eosinophil-deficient murine strains was observed except for the significant decrease of DC frequency in $\mathrm{Ccr} 3 \mathrm{KO}$ mice (Supplementary Figure S2). Similarly, there was no significant reduction in mononuclear cell populations in these mice (Figure 2a).

The weight and total cell number of PP were significantly reduced in eosinophil-deficient mice, implying a role of eosinophils in the normal development of PP (Figure 2b and c). As total cell numbers of PP were reduced, the absolute numbers of $\mathrm{CD}^{+}, \mathrm{CD}^{+}$, and $\mathrm{CD} 19^{+}$cells and of DCs and pDCs were decreased in eosinophil-deficient mice (data not shown), although the frequencies of $\mathrm{CD}^{+}$cells in the 

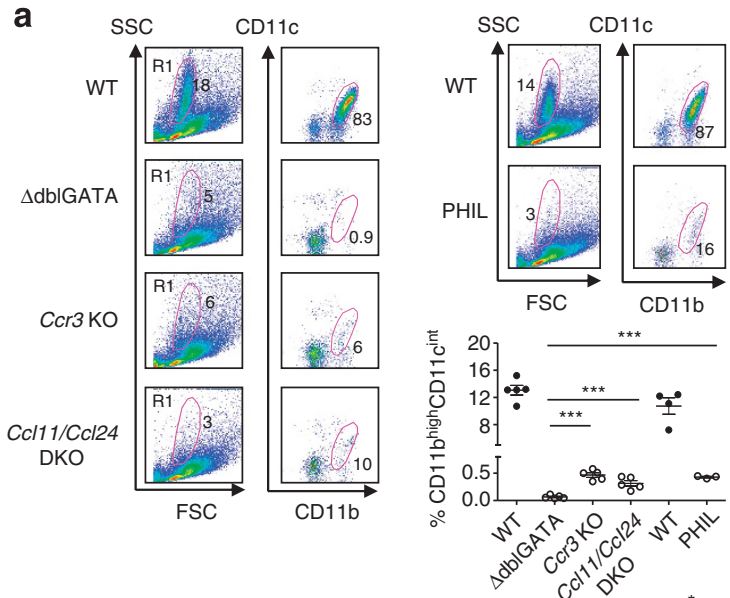

C
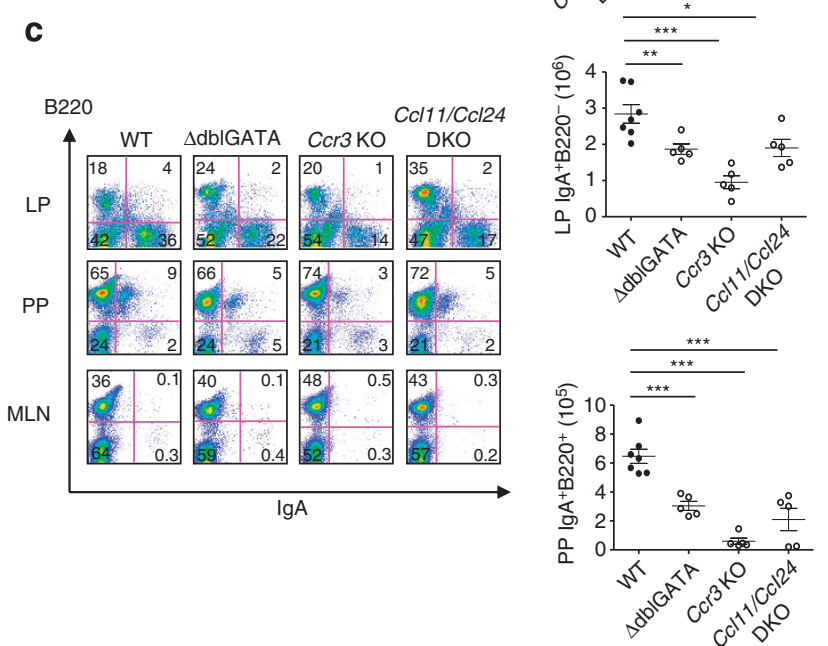
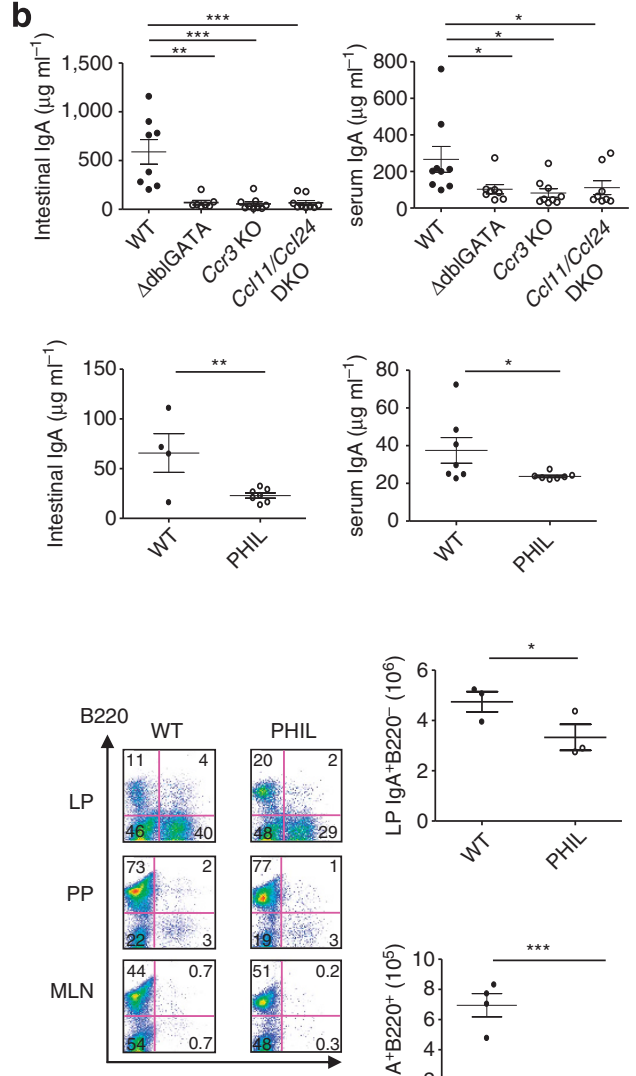

$\lg A$

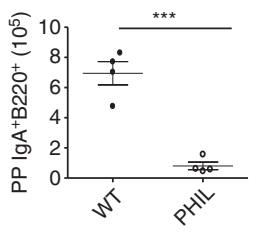

Figure 1 Reduced immunoglobulin A (IgA) levels in serum and intestinal lavage of eosinophil-deficient mice and their decreased lgA ${ }^{+}$cell numbers in the small intestine and Peyer's patches (PP). (a) The small intestinal lamina propria (LP) cells of the wild-type (WT; black circles), $\triangle$ dbIGATA, CC chemokine receptor 3-deficient (Ccr3 knockout (KO)), eotaxin-1/2 double-deficient (Cc/11/Ccl24 double knockout (DKO)), and PHIL mice (eosinophil deficient; white circles). The frequencies of CD11 $b^{\text {high }} C D 11 c^{\text {int }}$ small intestinal eosinophils were analyzed with R1-gated cells

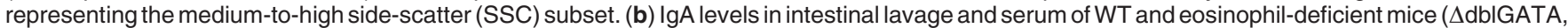
Ccr3 KO, Ccl11/Ccl24 DKO, and PHIL). (c) Frequencies and/or numbers of IgA ${ }^{+}$cells in the small intestinal LP, PP, and mesenteric lymph nodes (MLN) of WT, $\triangle \mathrm{dbIGATA}, C \mathrm{Cr} 3 \mathrm{KO}, \mathrm{Cc} / 11 / \mathrm{Ccl} 24 \mathrm{DKO}$, and PHIL mice. The IgA ${ }^{+}$cell number was calculated by multiplying the total cell number of each tissue by the frequency of $\lg \mathrm{A}^{+}$cells in that tissue. All data are representative of two or more independent experiments. Data are mean \pm s.e.m. values. ${ }^{*} P<0.05,{ }^{* *} P<0.01$, and ${ }^{* \star *} P<0.001$ (Student's $t$-test).

PP were modestly increased in $\triangle$ dblGATA and $C c r 3 \mathrm{KO}$ mice (Supplementary Figure S2). $\Delta$ dblGATA, Ccr3 KO, Ccl11/ Ccl24 DKO, and PHIL mice did not show a significant difference compared to WT mice in their weight, cellularity, and immune cell populations in MLN (data not shown).

\section{Adoptively transferred small intestinal LP cells restore IgA synthesis in $\triangle \mathrm{dbIGATA}$ mice}

To prove that the IgA deficiency observed in $\triangle$ dblGATA mice was an acquired defect secondary to the altered intestinal immunity rather than a defect directly caused by the genetic engineering or other occult differences between WT and $\triangle$ dblGATA mice, we assessed whether IgA deficiency was reversed by adoptive transfer of small intestinal LP cells. Ideally, we would have transferred purified LP eosinophils, but getting sufficient number of LP eosinophils from the small intestine for transfer was not technically feasible. Accordingly, we isolated small intestinal LP cells from WT mice and transferred into recipient $\Delta$ dblGATA mice. Analysis of the small intestine of reconstituted $\triangle$ dblGATA showed significantly increased sidescatter high (SSC ${ }^{\text {high }}$ ) and $\mathrm{CD} 11 \mathrm{~b}^{\text {high }} \mathrm{CD} 11 \mathrm{c}^{\text {int }}$ intestinal eosinophils although the degree of increase was modest (Supplementary Figure S3A). After 14 days of transfer, recipient mice showed increased numbers of small intestinal $\mathrm{IgA}^{+} \mathrm{B}_{220^{-}}$cells (Figure 3a) and intestinal IgA secretion (Figure 3b). We also observed significant restoration of weight and total cell number of PP in recipient mice (Supplementary Figure S3B), though $\mathrm{IgA}^{+} \mathrm{B}_{220^{+}}$number in PP of the recipient mice were not restored to the level of WT mice (Figure 3a). The failure of adoptively transferred LP cells isolated from the small intestine of $\triangle \mathrm{dblGATA}$ to restore IgA levels (Supplementary Figure S4A) suggests that the increased IgA in $\triangle$ dblGATA following adoptive transfer of WT LP cells was eosinophil dependent. However, it is hard to suggest that 

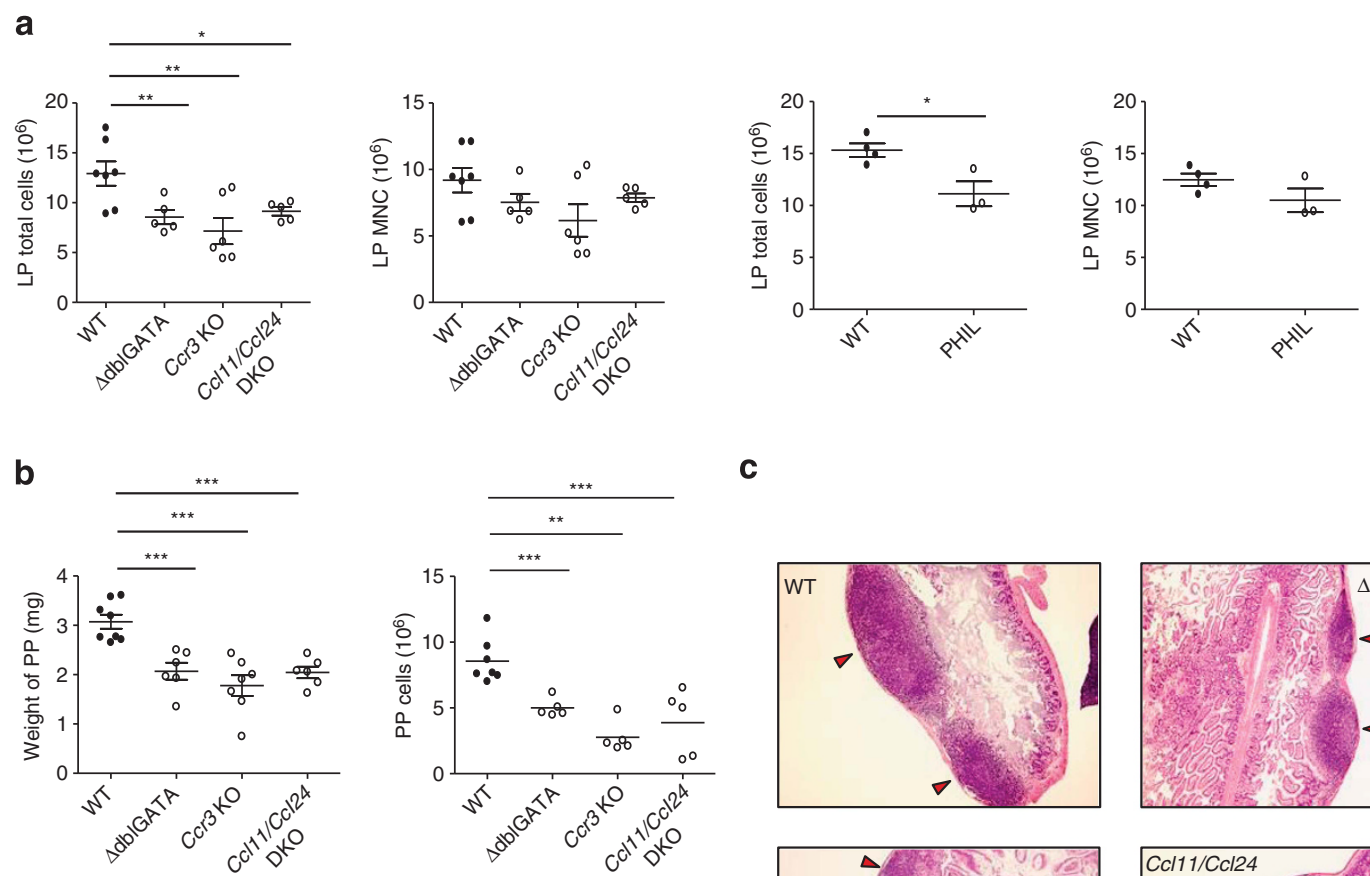

C
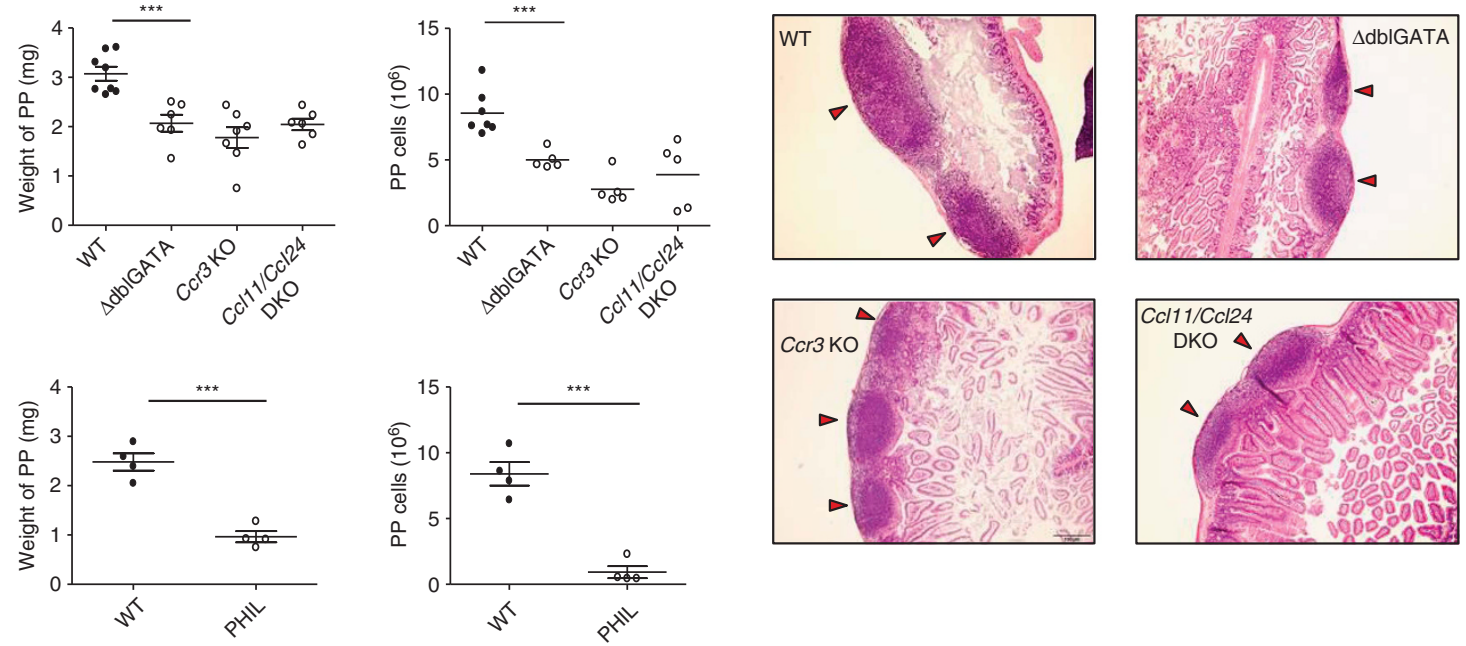

Figure 2 Small intestine and Peyer's patches (PP) immune cell populations in eosinophil-deficient mice and impaired PP development. (a) Total lamina propria (LP) cells and mononuclear cell (MNC) numbers in the small intestine of wild-type (WT; black circles), $\triangle \mathrm{db}$ IGATA, CC chemokine receptor 3-deficient (Ccr3 knockout (KO)), eotaxin-1/2 double-deficient (Ccl11/Ccl24 double knockout (DKO)), and PHIL mice (eosinophil deficient; white circles). (b) Weight and cell numbers of PP isolated from WT and eosinophil-deficient mice. (c) Hematoxylin and eosin staining of PP in WT and eosinophil-deficient mice. Arrowheads indicate PP in the small intestine. Original magnification $\times 10$. All data are representative of two or more independent experiments with $n \geqslant 3$ mice. Data are mean \pm s.e.m. values. ${ }^{\star} P<0.05,{ }^{* \star} P<0.01$, ${ }^{\star \star *} P<0.001$ (Student's $t$-test).

LP eosinophils directly promote IgA class switching of small intestinal $\mathrm{B}$ cells as the presence of $\mathrm{SSC}^{\text {high }} \mathrm{CD} 45^{+} \mathrm{MHC}$ II $^{-}$CD $11 b^{\text {high }} \mathrm{CD} 11 c^{\text {int }}$ small intestinal LP eosinophils did not induce a significant increase of IgA in cultures of B cells activated either with APRIL and BAFF or cecal bacterial antigen (Figure $3 \mathrm{c}$ and Supplementary Figure S3C).

\section{Reduced mucus secretion and less efficient induction of oral tolerance in $\triangle \mathrm{dbIGATA}$ mice}

A significant decrease in IgA synthesis in eosinophil-deficient mice was accompanied by reduced mucus secretion in the small intestine of $\Delta$ dblGATA mice as demonstrated by wheat germ agglutinin stains (Figure 4a) and by periodic acid-Schiff stains (Supplementary Figure S5). Accordingly, the number of mucus-expressing goblet cells present in the epithelial layer of the villi was significantly decreased in the small intestine of $\triangle$ dblGATA mice (Supplementary Figure S5B). The mucus layer of the intestine provides a physical barrier for the underlying intestinal epithelium against adhesion and invasion by microorganisms, bacterial toxins, and antigens. ${ }^{19}$ Recently, it has been reported that mucus enhances intestinal homeostasis, as well as oral tolerance, by delivering tolerogenic signals to DCs in the intestine. ${ }^{20}$ Therefore, $\triangle$ dblGATA and WT mice were tolerized orally to ovalbumin (OVA) to examine whether the development of oral tolerance was altered in eosinophildeficient mice. Mice were fed $1 \%$ OVA in drinking water for five days. After intraperitoneal sensitization and boost, OVAspecific serum IgG1, IgG2a, and IgE were compared between tolerized (Tol group) and systemically immunized mice without OVA (IP group). As shown in Figure $\mathbf{4 b}$, there was a significant difference between the WT and eosinophil-deficient Tol groups of mice; the OVA-specific IgG1, IgG2a, and IgE levels were significantly higher in the tolerized $\triangle$ dblGATA mice compared with the WT mice $(P=0.0151, P=0.0416$, and $P=0.0375$, respectively, Figure $\mathbf{4 b}$ ). Also, as for OVA-specific IgE, the IP group of the $\triangle$ dblGATA mice showed a significant increase $(P=0.0180)$ relative to the same group of WT mice, though no significant differences were observed in the OVA-specific IgG1 $(P=0.4177)$ or IgG2a $(P=0.4867$; Figure $4 b)$. Taken together, our observations demonstrate that although oral tolerance successfully developed in $\triangle$ dblGATA mice, the degree was inefficient compared to WT mice, consistent with the decrease 
a
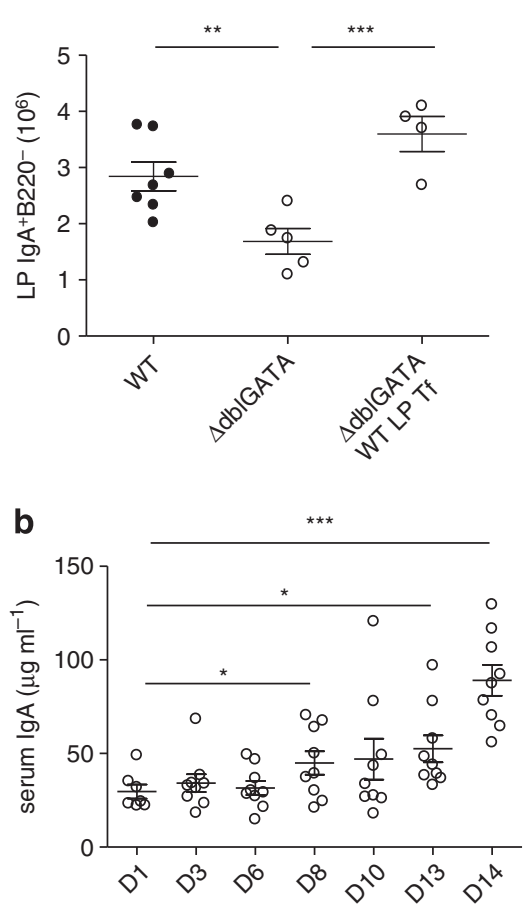

C

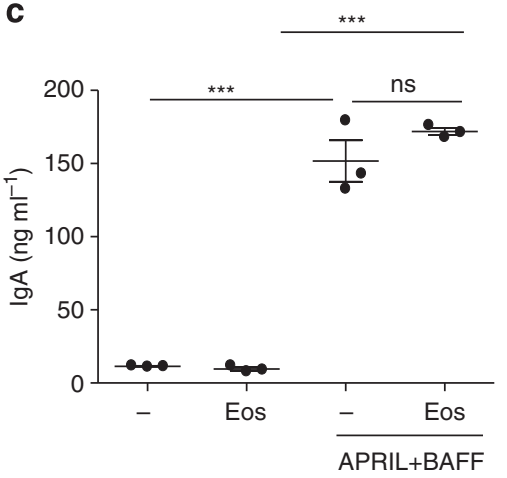

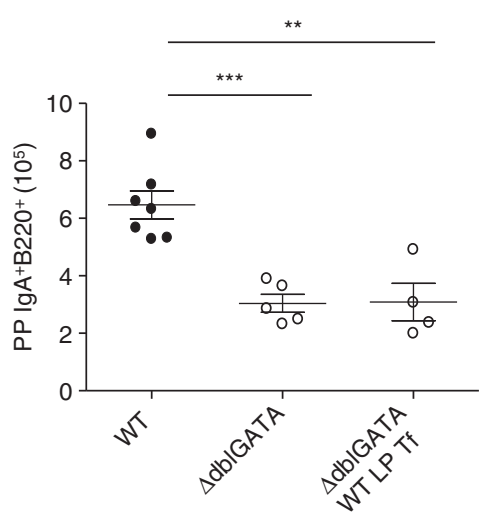
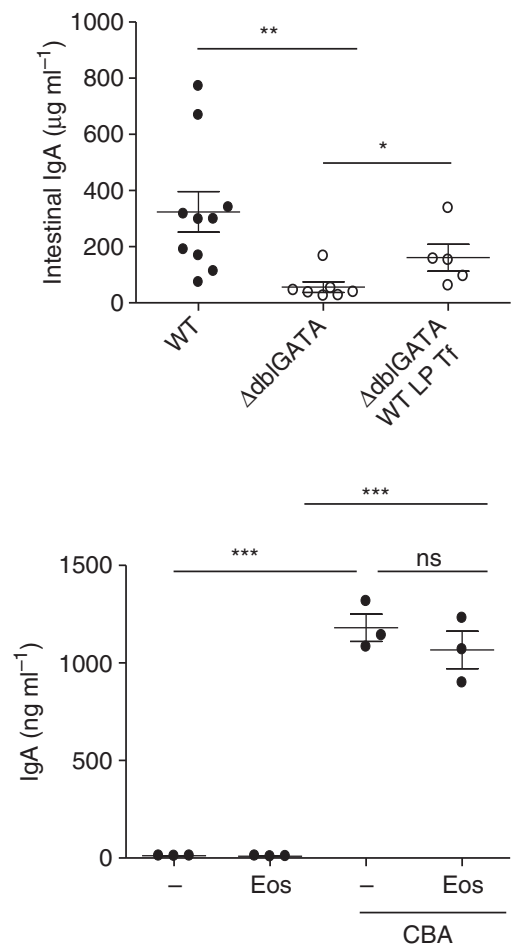

Figure 3 Effect of adoptively transferred small intestinal lamina propria (LP) cells on immunoglobulin A (IgA) synthesis in $\triangle$ dblGATA mice. (a) Numbers of $\lg \mathrm{A}^{+}$cells in the LP of small intestine and Peyer's patches (PP) of wild-type mice (WT; black circles), $\triangle$ dblGATA (eosinophil-deficient; white circles), and $\Delta \mathrm{db}$ IGATA mice after adoptive transfer of small intestinal LP cells isolated from WT mice ( $\Delta \mathrm{db}$ IGATA WT LP adoptive Tf; white circles). ${ }^{* \star} P<0.01$ and ${ }^{\star * \star} P<0.001$ (Student's $t$-test). (b) IgA levels in serum of $\Delta$ dbIGATA mice were analyzed over the indicated time period after adoptive transfer of WT LP cells. IgA levels in intestinal lavage of WT, $\Delta$ dblGATA mice, and $\Delta$ dblGATA mice 14 days after adoptive transfer of WT LP cells. ${ }^{*} P<0.05,{ }^{* *} P<0.01$, and ${ }^{* * *} P<0.001$ (Student's $t$-test). (c) Naive B cells isolated from the small intestine of WT mice were cultured with the indicated stimuli in the presence or absence of small intestinal eosinophils for 7 days. IgA production by stimulated B cells was determined by ELISA. All data are representative of two or more independent experiments. Data are mean \pm s.e.m. values. ${ }^{\star \star \star} P<0.001$ (Student's $t$-test). ns, not significant.

in intestinal mucus content, which has been suggested to modulate oral tolerance. ${ }^{20}$

\section{Expression of Lta and $L t b$ are decreased in the small intestine of $\triangle \mathrm{db}$ IGATA mice}

APRIL, BAFF, and TGF- $\beta$ in the GI tract synergistically support T cell-independent IgA class switching, and TGF- $\beta$ is also required for $\mathrm{T}$ cell-dependent IgA class switching in organized lymphoid tissue. ${ }^{7,21,22}$ Therefore, we analyzed the expression level of these cytokines in the small intestine and PP of WT and $\triangle$ dblGATA mice. As shown in Figure 5a, levels of
Tnfsf13, Tnfsf13b, and Tgfbl mRNA in the small intestine and PP of $\Delta$ dblGATA mice were not different compared to WT mice as suggested by insignificant effect of small intestinal LP eosinophils on the IgA class switching observed in B cell cultures (Figure 3c). Consistent with these results, gene expressions for $T n f s f 13, T n f s f 13 b$, and $T g f b 1$ were not considerable in isolated eosinophils from the small intestine (Figure 5b), thus suggesting another mechanism for the decrease in IgA in eosinophil-deficient mice. In addition, expression of matrix metalloproteinase 9 and thrombospondin 1 mRNAs, responsible for the activation of latent form of TGF- $\beta,{ }^{23,24}$ were 
a

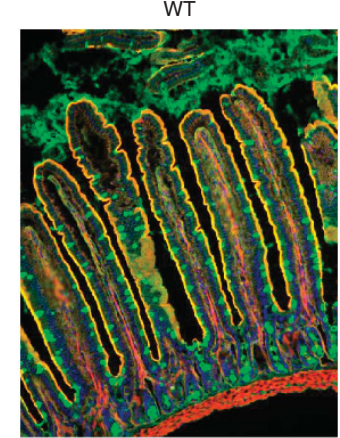

$\triangle \mathrm{dbIGATA}$
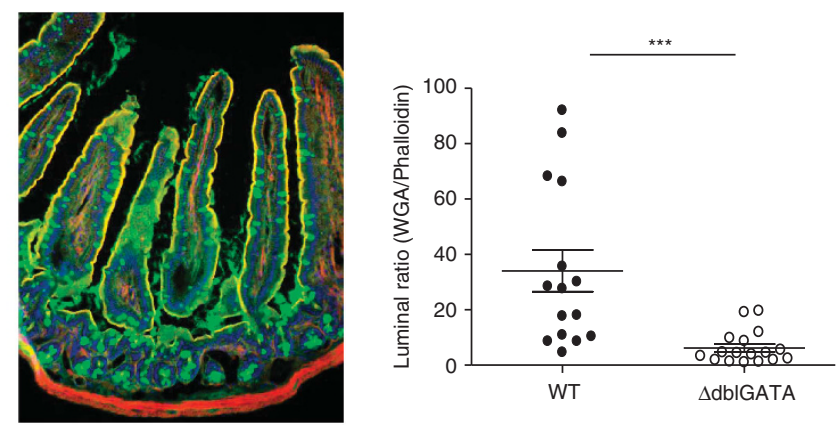

WGA Phalloidin DAPI
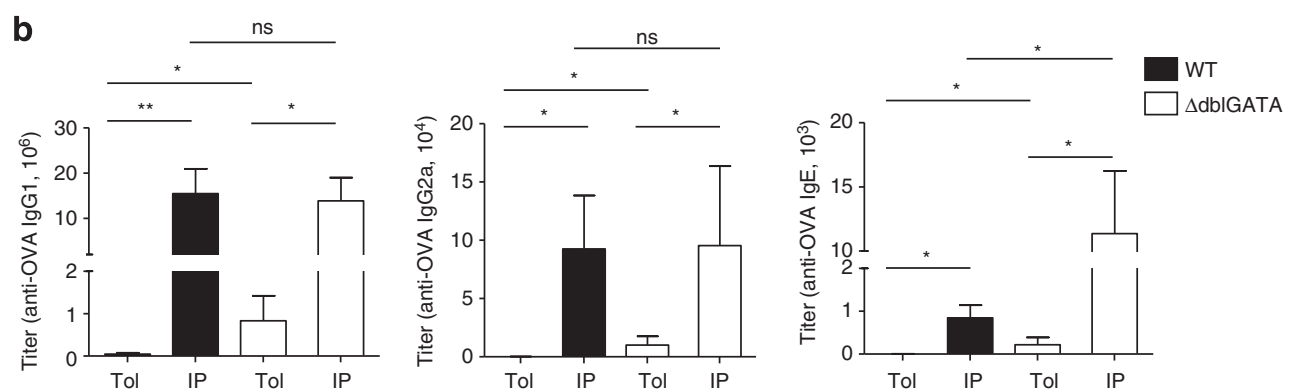

Figure 4 Decreased mucus secretion and less efficient induction of oral tolerance in $\triangle \mathrm{dblGATA}$ mice. (a) The mucus layer of wild-type (WT) and $\triangle \mathrm{dbIGATA}$ were visualized by immunofluorescence staining of small intestine with wheat germ agglutinin (WGA; green) and phalloidin (red). Sections were counterstained with DAPI (blue). Original magnification $\times 40$. The WGA-positive and phalloidin-positive luminal areas were measured using Imaris software. Three sections were examined in each group (WT, black circles; $\triangle \mathrm{dblGATA}$, white circles) and five to six fields were selected from one section. ${ }^{* * *} P<0.001$ (Student's $t$-test). (b) Ovalbumin (OVA)-specific serum immunoglobulin (Ig) G1, IgG2a, and IgE titers were compared among OVA-fed, sensitized mice (Tol) and sensitized mice without OVA (IP) in WT and $\triangle \mathrm{db}$ IGATA mice. The data are representative of more than three independent experiments. Data are mean \pm s.e.m. values. ${ }^{\star} P<0.05$ and ${ }^{* *} P<0.01$ (Student's $t$-test). ns, not significant.

not decreased in the small intestine of $\Delta$ dblGATA mice, although their expressions were considerable in the small intestinal eosinophils (Supplementary Figure S6A).

Recently, it has been reported that LT controls IgA production in the small intestine ${ }^{12}$ and also induces the development of gut-associated lymphoid tissues including $\mathrm{PP}^{25}$ As we observed decreased IgA synthesis and impaired PP development in eosinophil-deficient mice, we examined $L t a$ and $L t b$ expression in $\Delta$ dblGATA mice. As shown in Figure $5 \mathbf{c}, L t b$ mRNA and Lta mRNA, to a lesser extent, were significantly decreased in the small intestine but not in the PP of $\Delta$ dblGATA mice. Consistent with this, RNA microarray data from sorted WT small intestinal eosinophils indicate a considerable level of $L t b$ mRNA and barely expressed Lta (Figure 5d). As the difference of $L t a$ between WT and $\Delta$ dblGATA mice was reduced when the expression of Lta was normalized to leukocyte-specific protein tyrosine phosphatase, receptor-type C (Supplementary Figure S6B), the significant decrease of Lta in the small intestine of $\Delta$ dblGATA mice may be reflective of the decrease of total LP leukocytes in these mice (Figure 2a). However, considering the low level of Lta mRNA in the WT small intestinal eosinophils, the major population of cells missing in the WT small intestine of $\triangle$ dblGATA (Figure 1a), we suggest that the distribution of LT- $\alpha$ in other leukocyte subsets could be considerable as LT- $\alpha$ is a soluble protein, whereas LT- $\beta$ is a membrane-bound molecule associated with leukocytes. ${ }^{26}$

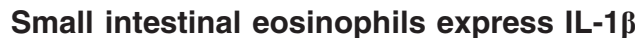

Small intestinal eosinophils were found to robustly express a high level of $I l 1 b$ (Figure 6a) as determined by the raw signal of RNA microarray of fluorescence-activated cell sorting (FACS)-sorted cells and in comparison to levels of Il23a, Il25, Il33, Il2, and Il7, genes for cytokines involved in intestinal immunity including stimulation of ILCs. ${ }^{27,28}$ In line with the predominant presence of eosinophils in the small intestine, $I l 1 b$ expression was decreased only in the small intestine and not in the PP of $\triangle$ dblGATA mice, thus suggesting eosinophils as a major source for IL- $1 \beta$ production in the small intestine (Figure $\mathbf{6 b}$ ). Eosinophils isolated from the small intestine also expressed low levels of caspase $1 \mathrm{mRNA}$ (Casp1, raw expression value of $302.6 \pm 17.0$, with a significance threshold of 400), known to activate the precursor form of IL-1 $\beta$, ${ }^{29}$ and the production of IL- $1 \beta$ by small intestinal eosinophils was confirmed by detection of secreted IL-1 $\beta$ protein from cultured small intestinal LP eosinophils (Figure 6c). Accordingly, small intestinal segments of WT mice showed significantly higher IL-1 $\beta$ levels than those of $\Delta$ dblGATA mice, and the expression of IL- $1 \beta$ in the WT small intestine was decreased from the proximal to the distal segment compatible with intestinal distribution of eosinophils as reported previously (Figure 6d). ${ }^{30}$

\section{IL-1 $\beta$ regulates SIgA production}

Notably, IL-1 $\beta$ can stimulate proliferation of ROR- $\gamma \mathrm{t}^{+}$ ILCs $^{31,32}$ and also enhance iNOS expression, ${ }^{33,34}$ an enzyme 
a
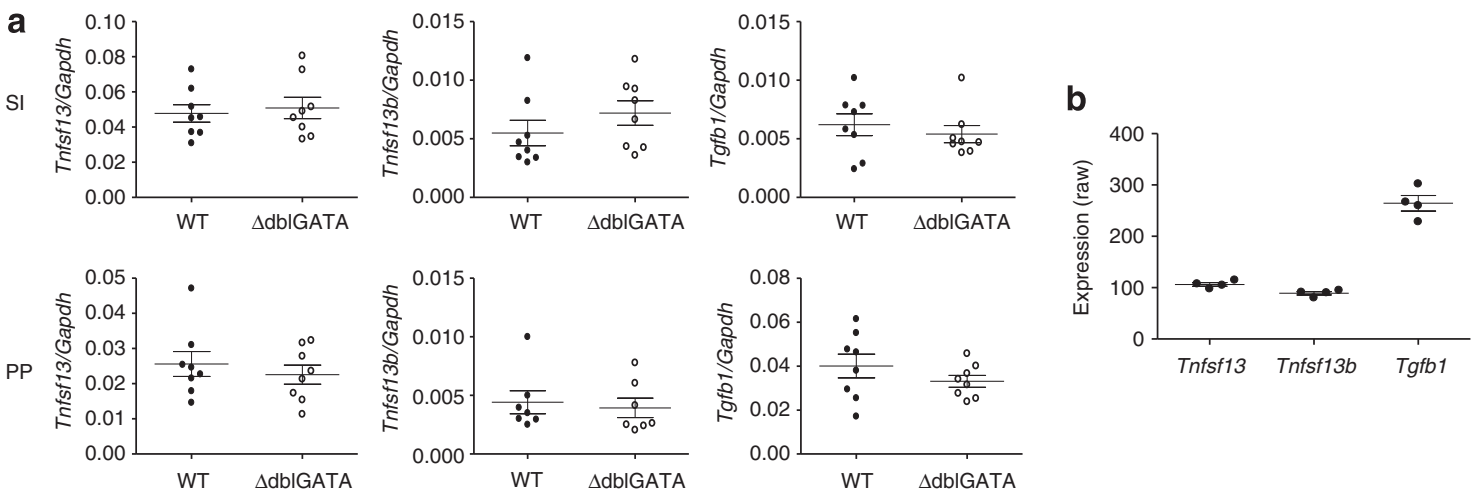

C
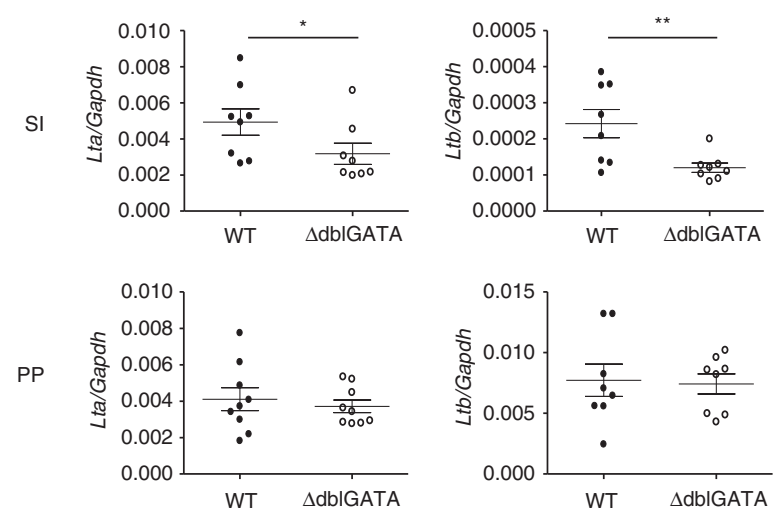

d

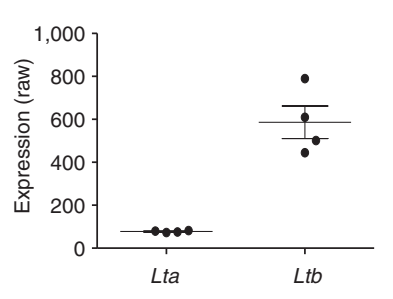

Figure 5 Expression of lymphotoxin $\alpha(L t a)$ and $\beta(L t b)$ are decreased in the small intestine of $\Delta$ dblGATA mice. (a) Levels of a proliferationinducing ligand (Tnfsf13), B cell-activating factor of the tumor necrosis factor (Tnfsf13b), and transforming growth factor $\beta$ (Tgfb1) mRNA in the small intestine (SI) and Peyer's patches (PP) of wild-type (WT; black circles) and $\Delta$ dblGATA (white circles) mice. (b) Eosinophils isolated from the small intestine of WT mice were subjected to genome-wide mRNA microarray using Affymetrix mouse ST 1.0 chip. The raw expression values of Tnfsf13, Tnfsf13b, and Tgfb1 were displayed, with a threshold value of 400 units regarded as significant expression. (c) Levels of Lta and Ltb mRNA in the small intestine and PP of WT and $\Delta$ dbIGATA mice. (d) The Affymetrix raw expression value of $L$ ta and $L t b$ in eosinophils isolated from the small intestine of WT mice. All data, except for microarray analysis, are representative of two or more independent experiments.

Data are mean \pm s.e.m. values. ${ }^{*} P<0.05$ and ${ }^{* *} P<0.01$ (Student's $t$-test).

that has been shown to regulate IgA class switching. ${ }^{10,11}$ Therefore, we investigated whether frequency of $\operatorname{IgA}^{+}$cells is affected in $I l 1 b \mathrm{KO}$ mice. As shown in Figure 7a, $I l 1 b \mathrm{KO}$ mice evidenced a significant decrease of small intestinal IgA ${ }^{+}$cells and reduced intestinal IgA levels, although gene expression for $\operatorname{Tnfsf13}$, Tnfsf13b, and $T g f b 1$ in the small intestine was comparable to that of WT mice (Supplementary Figure S7A). Ill $b$ KO mice also showed decreased ROR- $\gamma \mathrm{t}^{+}$ILCs, and in line with this finding, the expression of Lta and Ltb mRNA was significantly decreased in the small intestine of $I l 1 b \mathrm{KO}$ mice, who also had decreased PP weight (Figure $7 \mathbf{b}$ and Supplementary Figure S7B). Illb KO mice also showed decreased Nos2 expression in the small intestine (Figure 7c). Collectively, these findings demonstrate a novel contribution of IL-1 $\beta$ for the regulation of intestinal immune system and suggest that decreased IL-1 $\beta$ stimuli in the small intestine are responsible for defective IgA production in $\triangle$ dblGATA mice. Consistent with findings in $I l 1 b \mathrm{KO}$ mice, $\Delta$ dblGATA mice showed decreased numbers of ROR- $\gamma \mathrm{t}^{+}$ILCs in the LP of the small intestine, which was not restored by adoptive transfer of LP cells isolated from the small intestine of Illb KO mice (Figure 7d and Supplementary Figure S4C). As a control, expression of c-Kit (a.k.a. CD117) and IL-7R $\alpha$, which are surface phenotype markers for ILCs, were comparable between $\triangle$ dblGATA and WT mice (Supplementary Figure S7C). In addition, we observed a significant decrease in Nos 2 expression in the small intestine but not in the PP of $\Delta$ dblGATA mice (Figure 7e).

\section{Changes in the microbiota of $\triangle \mathrm{dbIGATA}$ mice}

As both SIgA and mucus have been shown to affect luminal microflora composition, ${ }^{35,36}$ we analyzed microflora in eosinophil-deficient mice. Deep sequencing analysis of commensal microflora in WT and $\triangle$ dblGATA revealed a marked increase in Firmicutes-containing segmented filamentous bacteria and a decrease in Bacteroidetes in $\triangle$ dblGATA mice (Figure 8a), which could be reversed by adoptive transfer of WT LP cells isolated from the small intestine (Supplementary Figure S8A). Realtime PCR of selected intestinal commensals verified increased segmented filamentous bacteria and reduced Bacteroidetes in $\Delta$ dblGATA mice irrespective of whether they were separated, from or housed with WT mice for $>3$ weeks (Figure 8b; Supplementary Figure S8B). Intestinal commensal bacteria affect the development and maturation of organized lymphoid tissue. $^{36}$ As we observed impaired PP development in $\Delta$ dblGATA, we investigated whether aberrant intestinal 

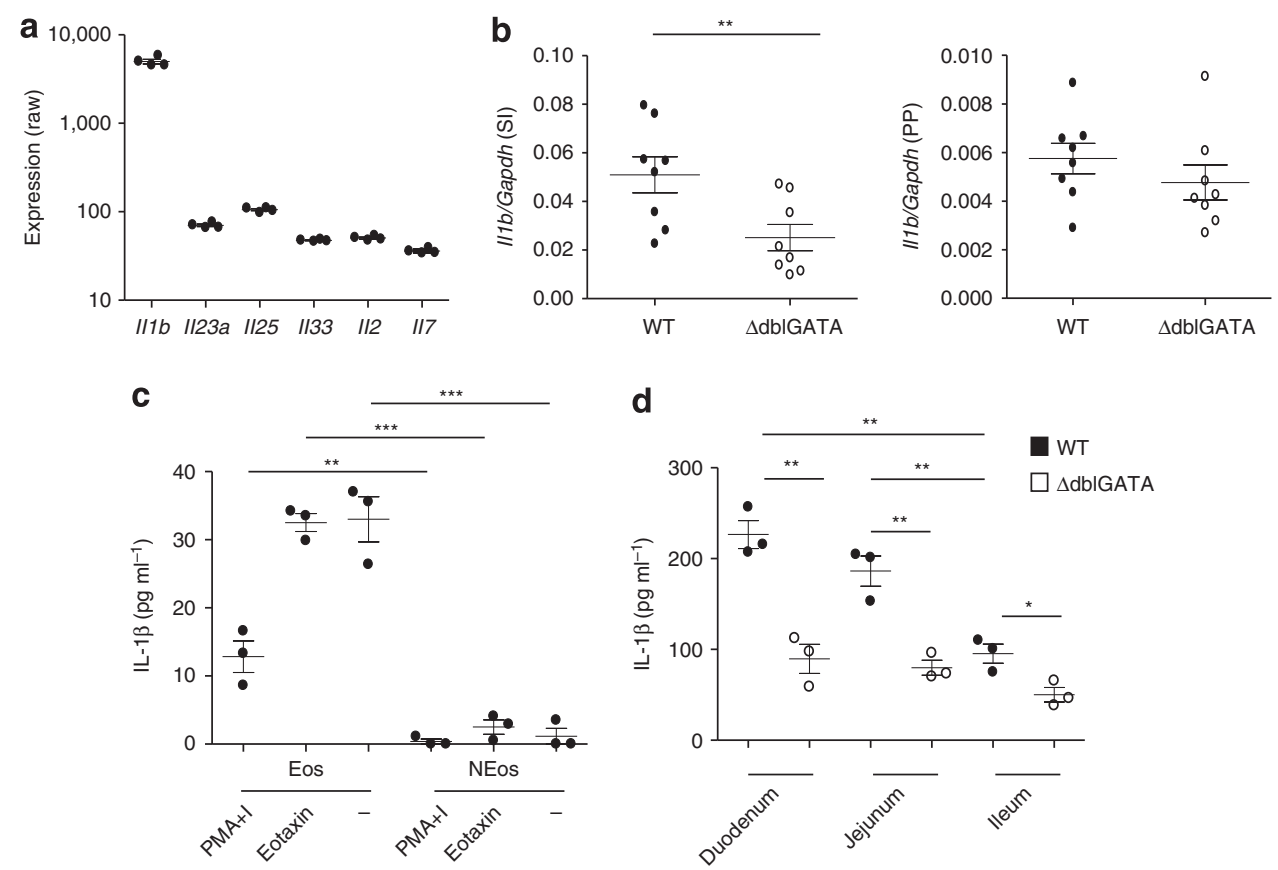

Figure 6 Small intestinal eosinophils actively express interleukin $1 \beta$ (IL-1 $\beta$ ). (a) The Affymetrix raw expression value of IL-1 $\beta$ (II1b), IL-23 (II23a), IL-25 (II25), IL-33 (I/33), IL-2 (II2), and IL-7 (II7) in eosinophils isolated from small intestinal lamina propria of wild-type (WT) mice, with a threshold value of 400 units regarded as significant expression. (b) $/ 11 \mathrm{~b}$ mRNA levels in the small intestine (SI) and Peyer's patches (PP) of WT (black circles) and $\triangle$ dbIGATA (white circles) mice. (c) IL-1 $\beta$ production was measured from cultures of small intestinal eosinophils (Eos) or non-eosinophil (NEos, $\mathrm{SSC}^{\text {low }} \mathrm{CD} 45^{+} \mathrm{MHC} \mathrm{II}{ }^{+} \mathrm{CD} 11 \mathrm{~b}^{-} \mathrm{CD} 11 \mathrm{c}^{-}$) subsets with the indicated stimuli for $24 \mathrm{~h}$. (d) IL-1 $\beta$ was detected with the indicated small intestinal segments of WT and $\triangle \mathrm{dbIGATA}$ mice; $1 \mathrm{mg}$ of protein extracted from each of the segment was loaded for ELISA. All data, except for microarray analysis, are representative of two or more independent experiments. Data are mean \pm s.e.m. values. ${ }^{\star} P<0.05,{ }^{\star \star} P<0.01,{ }^{\star \star \star}{ }^{\star *} P<0.001$ (Student's $t$-test).

microbiota in $\triangle$ dblGATA mice was connected with defective PP in these mice. IL-7 (Il7) is one of the central regulators of PP development, ${ }^{27}$ and commensal microflora promote steady-state IL-7 production in the epithelium of the intestine. ${ }^{37}$ As shown in Figure 8c, Il7 expression was decreased in the small intestine of $\Delta$ dblGATA mice. Taken together, these findings demonstrate a crucial role of eosinophils for the homeostatic interactions of the intestinal immune system with the gut microbiota, although further research is needed to determine whether the involved mechanisms are direct and/or indirect.

\section{DISCUSSION}

Eosinophils in the steady state are much more abundant in the LP of the intestines than in other tissues; ${ }^{1,38}$ however, their physiologic function has still remained largely unknown. In the present study, we demonstrate that eosinophils are required for mucosal production of IgA and development of PP, thus suggesting their important role in the maintenance of intestinal homeostasis. Recently, reduced IgA production has been reported in $\triangle \mathrm{dblGATA}$ and PHIL mice, strains with systemic eosinophil deficiency. ${ }^{39}$ By additionally examining Ccr3 KO and Ccl11/ Ccl24 DKO mice, which have selective eosinophil deficiency specific to the small intestine, ${ }^{40}$ we have substantiated these findings by demonstrating that eosinophils present in the small intestine are responsible for IgA production and PP development. As decrease in IgA in $\triangle$ dblGATA mice is partially restored by adoptively transferred small intestinal LP cells of WT mice but not by LP cells of $\Delta$ dblGATA (Supplementary Figure S4A), the acquired immune defect associated with eosinophil deficiency likely results in IgA reduction in $\triangle$ dblGATA mice. B cell-depleted LP cells of WT mice also had effects on the increase in IgA in $\triangle$ dblGATA mice, thus we suggest that $B$ cells of the recipient mice (but not donor $\operatorname{IgA}^{+} \mathrm{B}$ cells) account for the restoration of $\operatorname{IgA}$ following adoptive transfer (Figure S4A).

Our data presented herein suggest eosinophils regulate IgA class switching in the small intestine indirectly by altering the intestinal microenvironment to be more favorable for IgA production. The expression levels of $\operatorname{Tn} f s f 13, \operatorname{Tn} f s f 13 b$, and $T g f b 1$ genes for cytokines that directly induce IgA class switching were found to be comparable in the small intestine and PP of $\triangle \mathrm{dblGATA}$ mice with those of WT mice. This finding contrasts with the previous observations by Chu et al., ${ }^{39}$ which suggest that eosinophils are direct regulators of IgA production in the GI tract through their expression of IL-6, APRIL, and TGF- $\beta$ via Toll-like receptor (TLR)-mediated signaling. However, the $\mathrm{CD}_{11 \mathrm{~b}^{+}}{ }^{+}$iglecF ${ }^{+}$cell subset, which was used by $\mathrm{Chu}$ et al. for eosinophils, may include $\mathrm{CD} 11 \mathrm{~b}^{+}$small intestinal DCs (Supplementary Figure S9B), which are reported to produce IL-6 and directly induce IgA class switching in a TLR5-dependent way. ${ }^{41}$ In addition, though Chu et al. reported expression of TLR2, 4, 5, 7, and 9 in small intestinal eosinophils, the $\mathrm{CD}_{11 \mathrm{~b}}{ }^{+} \mathrm{DC}$ is the major subset 

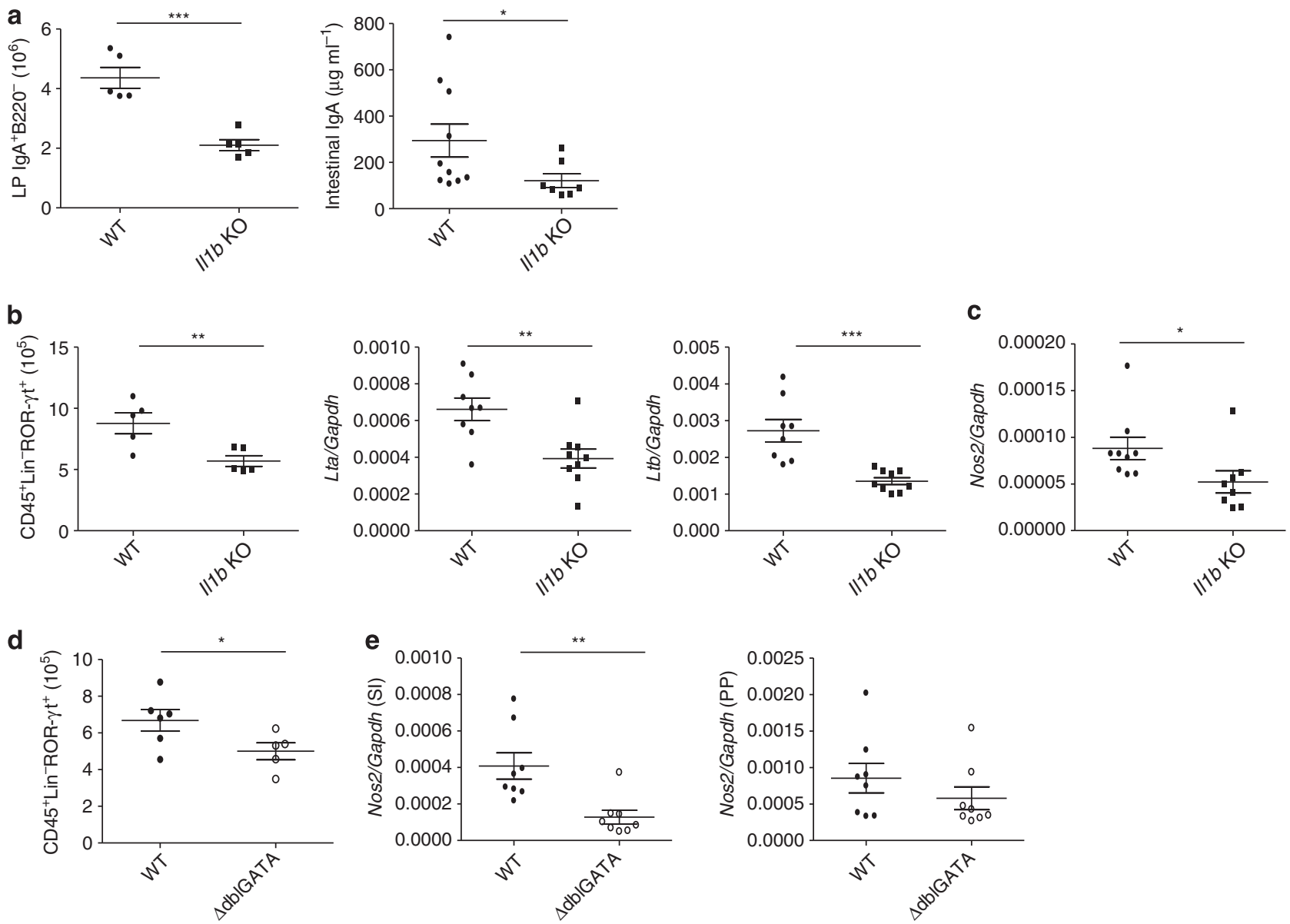

Figure 7 The level of retinoic acid-related orphan receptor gamma t-positive (ROR- $\gamma \mathrm{t}^{+}$) innate lymphoid cells (ILCs) and inducible nitric oxide synthase (iNOS, Nos2) expression in interleukin (IL) $1 \beta$-deficient (I/1b knockout (KO)) and $\Delta$ dblGATA mice. (a) Numbers of small intestinal lamina propria (LP) IgA ${ }^{+}$cells and intestinal IgA levels in wild-type (WT; black circles) and $/ 11 b$ KO (black squares) mice. (b) ROR- $\gamma \mathrm{t}^{+}$ILC numbers and expression of lymphotoxin $\alpha(L t a)$ and $\beta(L t b)$ mRNA in the small intestine of WT and $/ / 1 b \mathrm{KO}$ mice. Lineage marker (Lin) was the combination of CD3, B220, CD11c, and Gr-1. (c) Nos2 mRNA expressions in the small intestine of WT and //1b KO mice. (d) ROR- $\gamma \mathrm{t}^{+}$ILC numbers in the small intestine of WT and $\triangle$ dbIGATA (white circles) mice. (e) Nos2 mRNA expression in the small intestine (SI) and Peyer's patches (PP) of WT and $\triangle \mathrm{dbIGATA}$ mice. All data are representative of two or more independent experiments. Data are mean \pm s.e.m. values. ${ }^{*} P<0.05,{ }^{* *} P<0.01$, and ${ }^{* * \star} P<0.001$ (Student's $t$-test).

expressing TLR5 in the isolated small intestinal leukocytes, ${ }^{41}$ and we observed insignificant expression of these TLRs in sorted small intestinal eosinophils (raw expression values for TLR2, TLR4, TLR7, and TLR9 are $175.8 \pm 4.8,225.8 \pm 18.6$, $33.7 \pm 0.7$, and $119.3 \pm 6.7$, respectively, with a significance threshold of 400). In this study, CD11b ${ }^{+}$DCs were not included in eosinophils isolated from the small intestine (Supplementary Figures S3C and S9C), and isolated eosinophils expressed insignificant levels of Tnfsf13, $T n f s f 13 b$, and Tgfbl. Indeed, intestinal Il1b, Lta, Ltb, and Nos 2 expression and ROR- $\gamma \mathrm{t}^{+}$ILCs numbers were decreased in $\triangle$ dblGATA mice and showed a significant or almost significant increase after adoptive transfer of LP cells of WT mice (Supplementary Figure S4B and C). The decrease in IgA and ROR- $\gamma \mathrm{t}^{+}$ILCs and the altered gene expression profiles observed in $\triangle$ dblGATA were also seen in Il1b $\mathrm{KO}$ mice, implicating IL-1 $\beta$ expression by eosinophils in the control of intestinal homeostasis, which was supported by insignificant restoration of IgA, ROR- $\gamma \mathrm{t}^{+}$ILCs, and gene expressions in $\triangle$ dblGATA mice following adoptive transfer of small intestinal LP cells of Illb KO mice (Supplementary Figure S4). IgA is also known to regulate intestinal microbiota via shielding, immune exclusion, and modulating bacterial gene expression and maintaining healthy bacterial composition in the intestine. ${ }^{35}$ Therefore, mice having IgA defects show aberrant changes in microbial composition as represented by outgrowth of segmented filamentous bacteria and decrease in Bacteroidetes ${ }^{42,43}$ which are present in $\Delta$ dblGATA mice. Notably, Chu et al. observed changes in segmented filamentous bacteria and Bacteroidetes that were in the opposite direction of what we observed. ${ }^{39}$ The reasons for this difference are unclear, but both studies are consistent with a dominant role for eosinophils in regulating intestinal commensal microbiota. We propose that altered intestinal microbiota in eosinophil-deficient mice have a role in the impaired development of PP in these mice since $I l 7$, which is critical for PP development and regulated by commensal microflora, ${ }^{27,37}$ is significantly decreased in $\Delta$ dblGATA mice. 

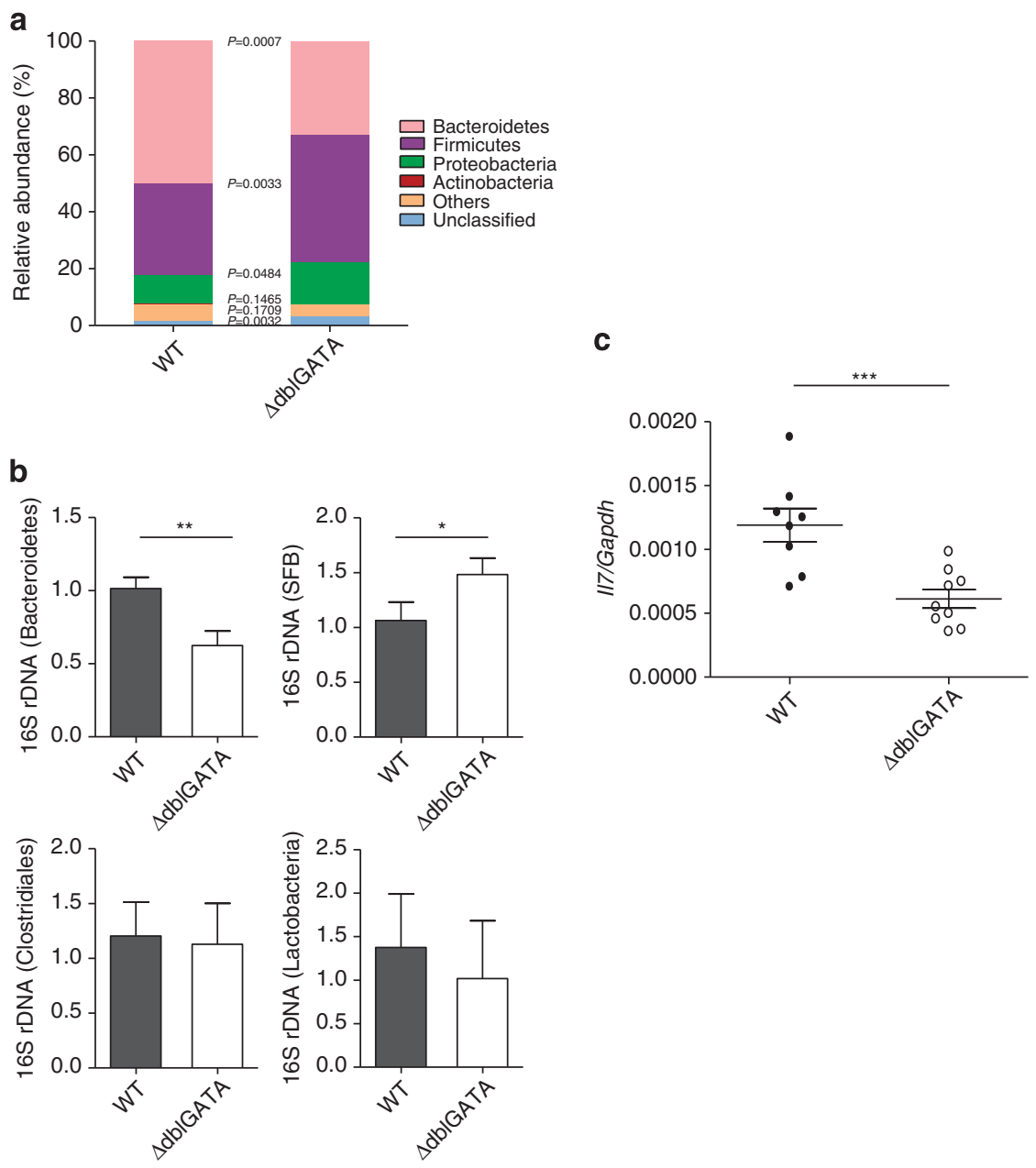

Figure 8 Changes in the microbiota of $\triangle \mathrm{dbIGATA}$ mice. (a) Sequencing analysis of microbiota composition from the stool of wild-type (WT) and $\triangle$ dbIGATA mice. Representative microbiota composition is presented ( $n=9$ mice per group). (b) Real-time PCR of microbiota in the stool of WT and $\triangle \mathrm{dblGATA}$ mice. (c) Interleukin 7 (II7) mRNA expression in the small intestine of WT (black circles) and $\triangle \mathrm{dblGATA}$ (white circles) mice. All data, except for sequencing analysis, are representative of two or more independent experiments. Data are mean \pm s.e.m. values. ${ }^{\star} P<0.05$, ${ }^{* *} P<0.01$, and ${ }^{* * *} P<0.001$ (Student's $t$-test). SFB, segmented filamentous bacteria.

The intestinal immune system protects against microbial pathogens and maintains a homeostatic interaction with commensal bacteria. In this environment, intestinal $\operatorname{Ig} \mathrm{A}$ neutralizes pathogenic toxins and microbes in a non-inflammatory manner, thereby promoting both immune protection and intestinal homeostasis. ${ }^{44}$ Intestinal IgA is synthesized through $\mathrm{T}$ cell-dependent and $\mathrm{T}$ cell-independent pathways. $^{6,45} \mathrm{~T}$ cell-dependent IgA class switching is initiated in the organized tissue, mainly in the PP, by CD40L signaling of activated T cells and cytokines, especially TGF- $\beta .^{46,47}$ Though the size and cellularity of PP in eosinophil-deficient mice are decreased, $\mathrm{CD} 40 \mathrm{~L}^{+}$T cell and $\mathrm{CD} 40^{+} \mathrm{B}$ cell frequencies in the PP of $\triangle$ dblGATA are normal and have genetic expression of Tgfb1 comparable to that of WT mice. These findings are consistent with the limited number of eosinophils in PP under the steady state ${ }^{16}$ and imply an indirect role of eosinophils in the impaired PP development in eosinophil-deficient mice.

APRIL, BAFF, and TGF- $\beta$ in the small intestine facilitate IgA class switching in the LP without help from activated $\mathrm{T}$ cells. $^{6,7}$ However, the gene expression levels of Tnfsf13, Tnfsf $13 b$, and Tgfbl were not affected in $\Delta$ dblGATA mice in accordance with the insignificant expression of these cytokines in isolated small intestinal eosinophils. We propose that eosinophils have a role in the maintenance of intestinal IgA through their expression of IL- $1 \beta$. LT produced by ROR$\gamma \mathrm{t}^{+}$ILCs induces T cell-independent IgA production in the LP of the small intestine even in the absence of PP and MLN. ${ }^{12,48}$ Considering that IL-1 $\beta$ promotes proliferation and LT expression of ROR- $\gamma \mathrm{t}^{+}$ILCs, ${ }^{31,32}$ it is reasonable to suggest that the selective decrease in IL- $1 \beta$ in the small intestine of $\Delta$ dblGATA mice is responsible for the reduction of ROR- $\gamma \mathrm{t}^{+}$ ILCs and LT expression. Our findings are also supported by the decrease in Nos2, an essential mediator for LT-dependent IgA production, ${ }^{12,49}$ in the small intestine of $\mathrm{Illb} \mathrm{KO}$ and $\triangle$ dblGATA mice. As Nos2 is barely expressed in small intestinal eosinophils (raw expression value $83.2 \pm 4.0$, threshold for significance being 400), it seems likely that small intestinal eosinophils are not the direct source of Nos2. IL-1 $\beta$ 
production by eosinophils is increased by SIgA, ${ }^{50}$ accordingly Ill $b$ mRNA expression was significantly higher in eosinophils isolated from the small intestine than eosinophils isolated from the lung (data not shown). In addition, secreted IgA enhances survival of eosinophils, ${ }^{50}$ and we observed considerable IgA signals in the cytoplasm of small intestinal eosinophils (Supplementary Figure S10), suggesting a positive feedback loop between IL-1 $\beta$-expressing eosinophils and IgA for the immune homeostasis in the gut.

The decrease in IgA in eosinophil-deficient mice was associated with an imbalanced homeostatic state in the GI tract, including decreased $\operatorname{IgA}$, mucus, and less efficient induction of oral tolerance, with the antibody titers of the tolerized $\Delta$ dblGATA mice being significantly increased relative to those of the tolerized WT mice. However, eosinophildeficient mice still successfully developed oral tolerance. Indeed, in contrast to the findings of Chu et al. ${ }^{39}$ we observed no significant differences between the $\triangle$ dblGATA and WT mice in the frequencies of $\mathrm{CD} 103^{+} \mathrm{DCs}$ and regulatory $\mathrm{T}$ cells, cells that are responsible for the development of oral tolerance $^{51,52}$ (Supplementary Figure S11). Considering the critical role of TGF- $\beta$ in the development of regulatory T cells, ${ }^{53}$ normal frequencies of regulatory $\mathrm{T}$ cells in $\triangle$ dblGATA mice corresponds with their level of $T g f b 1$ being comparable to that of WT mice.

In summary, we show that eosinophils are required for mucosal production of IgA and normal development of PP in the gut. Furthermore, we also demonstrate less efficient induction of oral tolerance and aberrantly changed intestinal microflora in the absence of eosinophils. Though the levels of Tnfsf 13 , Tnfsf13b, and Tgfb1 are maintained in eosinophildeficient mice, the decreases in ROR- $\gamma \mathrm{t}^{+}$ILC number and in expression of $L t a / L t b$ and Nos 2 indicate the eosinophils' role in the modulation of LT signaling-mediated IgA class switching. In addition, the decrease in IL-1 $\beta$ in the small intestine of eosinophil-deficient mice and the reduced production of $\operatorname{Ig} \mathrm{A}$ in Illb KO mice suggest that IL-1 $\beta$ is a key eosinophil-derived modulator of IgA class switching. Collectively, these findings demonstrate the crucial role of eosinophils in the homeostatic interactions with the intestinal immune system, and we propose on the basis of our findings that the involved mechanisms are unlikely to be largely dependent on eosinophil-derived APRIL and BAFF.

\section{METHODS}

Mice. $C c l 11 / C c l 24 \mathrm{DKO}$ and $C c r 3 \mathrm{KO}$ mice were generated as previously described. ${ }^{40} \Delta$ dblGATA were provided by Dr Stuart H Orkin (Howard Hughes Medical Institute, Chevy Chase, MD), PHIL mice were provided by James J Lee (Mayo Clinic, Rochester, MN), and Il1b KO mice were generated by Dr David Chaplin and provided by Dr Yui Hsi Wang. Littermate controls were used as WT controls for PHIL mice. In all experiments, we used 6- to 10-week-old, age- and sexmatched mice, which were housed in specific pathogen-free conditions at Cincinnati Children's Hospital Medical Center or Gachon University under an Institutional Animal Care and Use Committeeapproved protocol. All mice were housed at ambient temperature and a 12-hour light cycle.
Isolation of leukocytes from small intestinal LP, PP, and MLN. Segments of the small intestine were incubated with FACS buffer (phosphate-buffered saline (PBS) containing 10\% fetal calf serum (FCS), $20 \mathrm{~mm}$ 4-(2-Hydroxyethyl)piperazine-1-ethanesulfonic acid (HEPES), $100 \mathrm{U} \mathrm{ml}^{-1}$ penicillin, $100 \mu \mathrm{g} \mathrm{ml}^{-1}$ streptomycin, $1 \mathrm{~mm}$ sodium pyruvate, $10 \mathrm{~mm}$ EDTA, and $10 \mu \mathrm{g} \mathrm{ml}^{-1}$ polymyxin B) for $30 \mathrm{~min}$ at $37^{\circ} \mathrm{C}$ to remove epithelial cells and were washed extensively with PBS. Small intestinal segments, PP, and MLN were digested with $2.4 \mathrm{mg} \mathrm{ml}^{-1}$ collagenase A (Roche, Mannheim, Germany) and $10 \mu \mathrm{g} \mathrm{ml}^{-1}$ DNase I (Roche) in RPMI 1640/10\% FCS with continuous stirring at $37^{\circ} \mathrm{C}$ for $30 \mathrm{~min}$. Before enzyme digestion, weight of total isolated PP was measured using an analytical balance. EDTA was added (10 mm final), and the cell suspension was incubated for an additional $5 \mathrm{~min}$ at $37^{\circ} \mathrm{C}$. After washing, the cells were subjected to density-gradient centrifugation in 40\%/75\% Percoll (GE Healthcare, Piscataway, NJ). The cells harvested from the interface were washed and used as leukocytes in assays. For adoptive transfer assay, $1 \times 10^{7}$ isolated small intestinal LP cells were transferred into $\triangle$ dblGATA mice by intravenous injection.

Flow cytometry. To characterize the surface phenotype, the cells were isolated and resuspended in FACS buffer. After Fc receptor blocking with anti-mouse CD16/CD32 (2.4G2, BD Biosciences, San Jose, CA) for $15 \mathrm{~min}$ at $4{ }^{\circ} \mathrm{C}$, the cells were stained with antibodies against various markers. Anti-mouse B220 (RM3-6B2), CD11c (HL3), and ROR- $\gamma \mathrm{t}$ (Q31-378) were from BD Biosciences. Antibodies against CD11b (M1/ 70), CD45 (30-F11), CD3 (145-2C11), and Gr-1 (RB6-8C5) were from eBioscience (San Diego, CA). For IgA stain, the cells were fixed and permeabilized using the Cytofix/Cytoperm kit (BD Biosciences) and subsequently were stained intracellularly with anti-IgA (C10-3, BD Biosciences). Transcription Factor Buffer Set (BD Bioscience) was used for ROR- $\gamma$ t staining. Each sample was acquired with a FACSCalibur (BD Biosciences), and the data were processed with FlowJo software (Tree Star, Ashland, OR).

Cell culture. Cecal bacterial antigen was prepared as previously described. ${ }^{39}$ To induce IgA class switching, $1 \times 10^{5}$ of SSC SSw $^{\text {low }}$ $\mathrm{CD}_{4}{ }^{+} \mathrm{MHC} \mathrm{II}^{+} \mathrm{IgM}^{+} \mathrm{CD} 19^{+} \mathrm{B}$ cells isolated from the small intestine of WT mice were cultured with $100 \mu \mathrm{g} \mathrm{ml}^{-1}$ cecal bacterial antigen or APRIL $\left(100 \mathrm{ng} \mathrm{ml}^{-1}\right.$ ) plus BAFF $\left(50 \mathrm{ng} \mathrm{ml}^{-1}\right)$. An equal number of small intestinal eosinophils sorted as $\mathrm{SSC}^{\text {high }} \mathrm{CD} 45^{+}$ MHC II $^{-}$CD $11 b^{\text {high }} \mathrm{CD} 11 c^{\text {int }}$ were added to some of the B cell cultures to determine whether eosinophils directly support IgA class switching. To examine IL-1 $\beta$ secretion, sorted small intestinal eosinophils were cultured for $24 \mathrm{~h}$ in the presence of IL-5 $\left(10 \mathrm{ngml}^{-1}\right)$. In some experiments, phorbol myristate acetate $\left(20 \mathrm{ng} \mathrm{ml}^{-1}\right)$ and ionomycin $(1 \mu \mathrm{M})$ or eotaxin-1 $\left(25 \mathrm{ng} \mathrm{ml}^{-1}\right)$ were added for the stimulation of eosinophils.

Enzyme-linked immunosorbent assay. For determination of total IgA, 96-well plates were coated with anti-mouse IgA (C10-3, BD Pharmingen, San Diego, CA) and blocked with PBS/bovine serum albumin. Diluted serum or intestinal washes were incubated, and biotinylated anti-mouse IgA (C10-2, BD Pharmingen) was added. After reacting with streptavidin-horseradish peroxidase (HRP), the plates were developed with $3,3^{\prime}, 5,5^{\prime}$-tetramethylbenzidine (TMB) substrates (BD Pharmingen), and the absorbance was read at $450 \mathrm{~nm}$. A mouse IL-1 $\beta$ ELISA kit (R\&D Systems, Minneapolis, MN) was used according to the manufacturer's instructions to measure the levels of IL-1 $\beta$ in cell culture supernatants and small intestinal segments of WT and $\Delta$ dblGATA mice.

Immunohistochemistry and immunofluorescence. PP-containing small intestines were fixed in $10 \%$ formalin, routinely processed, and embedded in paraffin. Sections were stained with hematoxylin and eosin (H\&E). For immunofluorescence staining, fixed, frozen small intestinal sections were rehydrated in PBS for $30 \mathrm{~min}$ and permeabilized in $0.2 \%$ Triton X-100 (Fisher Scientific, Waltham, MA)/PBS for 
$10 \mathrm{~min}$. The slides were blocked with $1 \%$ bovine serum albumin/PBS for $1 \mathrm{~h}$ at room temperature and incubated with Alexa Fluor 488 wheat germ agglutinin (WGA, Molecular Probes, Eugene, OR) and Alexa Fluor 568 Phalloidin (Molecular Probes) for $30 \mathrm{~min}$. Sections were washed three times with PBS after each antibody incubation. After a 10 -min stain with DAPI, slides were mounted using ProLong Gold antifade (Molecular Probes). Sections were visualized using the BX51 microscope, DP72 camera, and DP2-BSW imaging software (Olympus America, Center Valley, PA). WGA-positive luminal signals were quantified using Imaris software (Bitplane, Zurich, Switzerland)

Induction of oral tolerance. Oral tolerance to OVA was induced as previously reported. ${ }^{54}$ Mice were provided 1\% OVA in drinking water ad libitum for 5 days, while a control group was given normal drinking water. Two days after the final oral treatment, immunization with OVA was performed via intraperitoneal injection of $100 \mu \mathrm{g}$ of OVA adsorbed to $1 \mathrm{mg}$ of aluminum hydroxide gel (Sigma-Aldrich, St. Louis, MO) ${ }^{55}$ Mice were boosted with $20 \mu \mathrm{g}$ of OVA in PBS 14 days after immunization, and blood samples were collected 7 days after antigen boost. OVA-specific IgG1, IgG2a, and IgE were analyzed as readout of oral tolerance induction. ${ }^{54,55}$

Real-time PCR. RNA from the small intestine and PP was extracted using QIAzol lysis reagent (Qiagen, Hilden, Germany) and subsequently column-purified with an RNeasy mini kit (Qiagen). RNA (500 ng) was treated with DNase I (New England Biolabs, Ipswich, MA), and cDNA was synthesized using the iScript cDNA synthesis kit (Bio-Rad, Hercules, CA). Real-time PCR was performed using iQ SYBR Green supermix (Bio-Rad). PCR was performed using a CFX96 real-time system (Bio-Rad). Sequences of primers are shown in Supplementary Table S1.

Genome-wide microarray analysis on sorted eosinophils. Microarray analysis on sorted intestinal eosinophils was performed as previously described. ${ }^{56}$ Small intestinal eosinophils were sorted as $\mathrm{DAPI}^{-} \mathrm{CCR}^{+}{ }^{+}$SiglecF ${ }^{+} \mathrm{CD} 45^{+} \mathrm{CD} 4^{-} \mathrm{CD} 8 \mathrm{a}^{-} \mathrm{CD} 19^{-} \mathrm{B}^{-} 20^{-} \mathrm{SSC}^{\text {high }}$ cells from 10 animals using FACSAria (BD Biosciences). Total RNA from sorted eosinophils was extracted by standard TRIzol RNA isolation (Invitrogen, Carlsbad, CA) and subsequently column-purified with an RNeasy mini kit (Qiagen). mRNA integrity was validated by the Agilent 2100 bio-analyzer (Agilent Technologies, Clara, CA). Eosinophil mRNA was amplified and labeled with the WT-Ovation Pico RNA amplification system (NuGen, San Carlos, CA) and subjected to the GeneChip Mouse Gene ST 1.0 Array chip (Affymetrix, Santa Clara, CA). Microarray expression analysis was performed at Cincinnati Children's Hospital Medical Center's Chip Core facility, and expression data were analyzed by the software of Genespring GX 11 (Agilent Technologies). The Affymetrix raw expression values were filtered with the significance threshold of 400 as previously reported ${ }^{56,57}$ and validated by the levels of eosinophil-specific major basic protein gene (also known as proteoglycan $2(\operatorname{Prg} 2))$ and eosinophil non-expressed glucagon ( $G c g$; Supplementary Figure S12).

Microbiota analysis. Genomic DNA was isolated from fresh or frozen ileum contents using the QIAamp fast DNA stool kit (Qiagen) according to manufacturer's instructions. Levels of the 16S rRNA gene of each bacterium were quantified by real-time PCR analysis as described above. The quantity of the $16 \mathrm{~S}$ rRNA gene from each bacterial group was normalized to the quantity of the eubacteria $16 \mathrm{~S}$ rRNA gene. Sequences of primers are shown in Supplementary Table S1. For deep sequencing, 16S rRNA was amplified using a combination of the universal bacterial/archael primers $515 \mathrm{~F}$ and $806 \mathrm{R}^{58}$ The $16 \mathrm{~S}$ rRNA sequence analysis was performed via MiSeq Reporter v2.3.32 (Illumina, San Diego, CA).

Statistical analysis. The data are presented as mean \pm s.e.m. All of the experiments were performed in triplicate. When necessary, a twogroup comparison was performed using the Student's $t$-test. A $P$ value $<0.05$ was considered statistically significant.
SUPPLEMENTARY MATERIAL is linked to the online version of the paper at http://www.nature.com/mi

\section{ACKNOWLEDGMENTS}

We thank the Cincinnati Digestive Health Center (P30 DK078392) Integrative Morphology Core for tissue processing, sectioning, histology, and immunohistochemical staining. We also thank Shawna Hottinger for editorial assistance. This work was supported by the NIH grants R37 Al045898 and R01 AI083450, the CURED (Campaign Urging Research for Eosinophilic Disease) Foundation, the Food Allergy Research \& Education (FARE), and Buckeye Foundation. Y.J. was supported by the Basic Science Research Program through the National Research Foundation of Korea funded by the Ministry of Education (2013R1A1A2004820). M.H.J. was supported by the Institute for Basic Science (IBS), Republic of Korea.

\section{DISCLOSURE}

M.E.R. is a consultant for Immune Pharmaceuticals, Celsus Therapeutics and Receptos and has an equity interest in each. $\mathrm{He}$ is an inventor of eosinophilic esophagitis-related patents owned by Cincinnati Children's Hospital Medical Center, some of which have been licensed to Diagnovus. $\mathrm{He}$ has a royalty interest in reslizumab, a drug being developed by Teva Pharmaceuticals. T.W. is a co-inventer of eosinophilic esophagitis-related patents owned by Cincinnati Children't Hospital Meical Center, some of which have been licensed to Diagnovus.

c 2015 Society for Mucosal Immunology

\section{REFERENCES}

1. Rothenberg, M.E. \& Hogan, S.P. The eosinophil. Annu. Rev. Immunol. 24 147-174 (2006).

2. Jung, Y. \& Rothenberg, M.E. Roles and regulation of gastrointestinal eosinophils in immunity and disease. J. Immunol. 193, 9991005 (2014).

3. Jacobsen, E.A., Helmers, R.A., Lee, J.J. \& Lee, N.A. The expanding role(s) of eosinophils in health and disease. Blood 120, 3882-3890 (2012).

4. Mishra, A., Hogan, S.P., Lee, J.J., Foster, P.S. \& Rothenberg, M.E. Fundamental signals that regulate eosinophil homing to the gastrointestinal tract. J. Clin. Invest. 103, 1719-1727 (1999).

5. Mowat, A.M. Anatomical basis of tolerance and immunity to intestinal antigens. Nat. Rev. Immunol. 3, 331-341 (2003).

6. Fagarasan, S., Kawamoto, S., Kanagawa, O. \& Suzuki, K. Adaptive immune regulation in the gut: Tcell-dependent and T cell-independent IgA synthesis. Annu. Rev. Immunol. 28, 243-273 (2010).

7. Cerutti, A. The regulation of IgA class switching. Nat. Rev. Immunol. 8, 421-434 (2008).

8. Lamm, M.E. \& Phillips-Quagliata, J.M. Origin and homing of intestinal IgA antibody-secreting cells. J. Exp. Med. 195, F5-F8 (2002).

9. Suzuki, K. \& Fagarasan, S. How host-bacterial interactions lead to IgA synthesis in the gut. Trends Immunol. 29, 523-531 (2008).

10. Tezuka, H. et al. Regulation of IgA production by naturally occurring TNF/ iNOS-producing dendritic cells. Nature 448, 929-933 (2007).

11. Lee, M.R., Seo, G.Y., Kim, Y.M. \& Kim, P.H. iNOS potentiates mouse Ig isotype switching through AID expression. Biochem. Biophys. Res. Commun. 410, 602-607 (2011).

12. Kruglov, A.A. et al. Nonredundant function of soluble LTalpha3 produced by innate lymphoid cells in intestinal homeostasis. Science 342, 1243-1246 (2013).

13. Chu, V.T. et al. Eosinophils are required for the maintenance of plasma cells in the bone marrow. Nat. Immunol. 12, 151-159 (2011).

14. Westlund, J., Livingston, M., Fahlen-Yrlid, L., Oldenborg, P.A. \& Yrlid, U. CD47-deficient mice have decreased production of intestinal IgA following oral immunization but a maintained capacity to induce oral tolerance. Immunology 135, 236-244 (2012).

15. Verjan Garcia, N. et al. SIRPalpha/CD172a regulates eosinophil homeostasis. J. Immunol. 187, 2268-2277 (2011).

16. Mishra, A., Hogan, S.P., Brandt, E.B. \& Rothenberg, M.E. Peyer's patch eosinophils: identification, characterization, and regulation by mucosal allergen exposure, interleukin-5, and eotaxin. Blood 96, 1538-1544 (2000). 
17. Carlens, J. et al. Common gamma-chain-dependent signals confer selective survival of eosinophils in the murine small intestine. J. Immunol. 183, 5600-5607 (2009).

18. Lee, J.J. et al. Defining a link with asthma in mice congenitally deficient in eosinophils. Science 305, 1773-1776 (2004).

19. Corazziari, E.S. Intestinal mucus barrier in normal and inflamed colon. J. Pediatr. Gastroenterol. Nutr. 48 (Suppl 2), S54-S55 (2009).

20. Shan, M. et al. Mucus enhances gut homeostasis and oral tolerance by delivering immunoregulatory signals. Science 342, 447-453 (2013).

21. Litinskiy, M.B. et al. DCs induce CD40-independent immunoglobulin class switching through BLyS and APRIL. Nat. Immunol. 3, 822-829 (2002).

22. Castigli, E. et al. TACl and BAFF-R mediate isotype switching in B cells. J. Exp. Med. 201, 35-39 (2005).

23. Crawford, S.E. et al. Thrombospondin-1 is a major activator of TGF-beta1 in vivo. Cell 93, 1159-1170 (1998).

24. Yu, Q. \& Stamenkovic, I. Cell surface-localized matrix metalloproteinase-9 proteolytically activates TGF-beta and promotes tumor invasion and angiogenesis. Genes Dev. 14, 163-176 (2000).

25. Alimzhanov, M.B. et al. Abnormal development of secondary lymphoid tissues in lymphotoxin beta-deficient mice. Proc. Natl. Acad. Sci. USA 94 9302-9307 (1997).

26. Ware, C.F. Network communications: Iymphotoxins, LIGHT, and TNF. Annu. Rev. Immunol. 23, 787-819 (2005).

27. Eberl, G. \& Lochner, M. The development of intestinal lymphoid tissues at the interface of self and microbiota. Mucosal Immunol. 2, 478-485 (2009).

28. Spits, H. \& Cupedo, T. Innate lymphoid cells: emerging insights in development, lineage relationships, and function. Annu. Rev. Immunol. 30 , 647-675 (2012)

29. Franchi, L., Munoz-Planillo, R. \& Nunez, G. Sensing and reacting to microbes through the inflammasomes. Nat. Immunol. 13, 325-332 (2012).

30. Chu, D.K. et al. Indigenous enteric eosinophils control DCs to initiate a primary Th2 immune response in vivo. J. Exp. Med. 211, 1657-1672 (2014).

31. Cella, M., Otero, K. \& Colonna, M. Expansion of human NK-22 cells with $\mathrm{IL}-7, \mathrm{IL}-2$, and IL-1beta reveals intrinsic functional plasticity. Proc. Natl. Acad. Sci. USA 107, 10961-10966 (2010).

32. Hughes, T. et al. Interleukin-1beta selectively expands and sustains interleukin-22 + immature human natural killer cells in secondary lymphoid tissue. Immunity 32, 803-814 (2010).

33. Carpenter, L., Cordery, D. \& Biden, T.J. Protein kinase Cdelta activation by interleukin-1beta stabilizes inducible nitric-oxide synthase mRNA in pancreatic beta-cells. J. Biol. Chem. 276, 5368-5374 (2001).

34. Adams, V. et al. Induction of iNOS expression in skeletal muscle by IL-1 beta and NFkappaB activation: an in vitro and in vivo study. Cardiovasc. Res. 54, 95-104 (2002).

35. Sutherland, D.B. \& Fagarasan, S. IgA synthesis: a form of functional immune adaptation extending beyond gut. Curr. Opin. Immunol. 24, 261-268 (2012)

36. Maynard, C.L., Elson, C.O., Hatton, R.D. \& Weaver, C.T. Reciprocal interactions of the intestinal microbiota and immune system. Nature 489 , 231-241 (2012).

37. Shalapour, S. et al. Commensal microflora and interferon-gamma promote steady-state interleukin-7 production in vivo. Eur. J. Immunol. 40, 2391-2400 (2010).

38. Rothenberg, M.E. Eosinophilic gastrointestinal disorders (EGID). J. Allergy Clin. Immunol. 113, 11-28. quiz 29 (2004).
39. Chu, V.T. et al. Eosinophils promote generation and maintenance of immunoglobulin-A-expressing plasma cells and contribute to gut immune homeostasis. Immunity 40, 582-593 (2014).

40. Pope, S.M., Zimmermann, N., Stringer, K.F., Karow, M.L. \& Rothenberg, M.E. The eotaxin chemokines and CCR3 are fundamental regulators of allergen-induced pulmonary eosinophilia. J. Immunol. 175, 5341-5350 (2005).

41. Uematsu, S. et al. Regulation of humoral and cellular gut immunity by lamina propria dendritic cells expressing Toll-like receptor 5. Nat. Immunol. 9, 769-776 (2008)

42. Suzuki, K. et al. Aberrant expansion of segmented filamentous bacteria in IgA-deficient gut. Proc. Natl. Acad. Sci. USA 101, 1981-1986 (2004).

43. Geuking, M.B., McCoy, K.D. \& Macpherson, A.J. The function of secretory IgA in the context of the intestinal continuum of adaptive immune responses in host-microbial mutualism. Semin. Immunol. 24, 36-42 (2012).

44. Macpherson, A.J., McCoy, K.D., Johansen, F.E. \& Brandtzaeg, P. The immune geography of IgA induction and function. Mucosal Immunol. 1, 11-22 (2008).

45. Cerutti, A. \& Rescigno, M. The biology of intestinal immunoglobulin A responses. Immunity 28, 740-750 (2008).

46. Bergqvist, P., Gardby, E., Stensson, A., Bemark, M. \& Lycke, N.Y. Gut IgA class switch recombination in the absence of CD40 does not occur in the lamina propria and is independent of germinal centers. J. Immunol. 177, 7772-7783 (2006)

47. Cazac, B.B. \& Roes, J. TGF-beta receptor controls B cell responsiveness and induction of IgA in vivo. Immunity 13, 443-451 (2000).

48. Kang, H.S. et al. Signaling via LTbetaR on the lamina propria stromal cells of the gut is required for IgA production. Nat. Immunol. 3, 576-582 (2002).

49. Fritz, J.H. et al. Acquisition of a multifunctional IgA + plasma cell phenotype in the gut. Nature 481, 199-203 (2012).

50. Bartemes, K.R., Cooper, K.M., Drain, K.L. \& Kita, H. Secretory IgA induces antigen-independent eosinophil survival and cytokine production without inducing effector functions. J. Allergy Clin. Immunol. 116, 827-835 (2005).

51. Coombes, J.L. et al. A functionally specialized population of mucosal CD103 + DCs induces Foxp3 + regulatory T cells via a TGF-beta and retinoic acid-dependent mechanism. J. Exp. Med. 204, 1757-1764 (2007).

52. Worbs, T. et al. Oral tolerance originates in the intestinal immune system and relies on antigen carriage by dendritic cells. J. Exp. Med. 203, 519-527 (2006).

53. Rubtsov, Y.P. \& Rudensky, A.Y. TGFbeta signalling in control of T-cellmediated self-reactivity. Nat. Rev. Immunol. 7, 443-453 (2007).

54. Mucida, D. et al. Oral tolerance in the absence of naturally occurring Tregs. J. Clin. Invest. 115, 1923-1933 (2005).

55. Tunis, M.C., Dawicki, W., Carson, K.R., Wang, J. \& Marshall, J.S. Mast cells and lgE activation do not alter the development of oral tolerance in a murine model. J. Allergy Clin. Immunol. 130, 705-715.e1 (2012).

56. Wen, T. et al. The pan-B cell marker CD22 is expressed on gastrointestinal eosinophils and negatively regulates tissue eosinophilia. J. Immunol. 188, 1075-1082 (2012).

57. Wen, T. et al. Carbonic anhydrase IV is expressed on IL-5-activated murine eosinophils. J. Immunol. 192, 5481-5489 (2014).

58. Bates, S.T. et al. Examining the global distribution of dominant archaeal populations in soil. ISME J. 5, 908-917 (2011). 